\title{
Alteração de temperatura na dentina durante o procedimento restaurador com resina composta variando as fontes fotopolimerizadoras
}


UNIVERSIDADE DE SÃO PAULO

FACULDADE DE ODONTOLOGIA DE RIBEIRÃO PRETO

\section{CRISTIANE SAVARIS}

Alteração de temperatura na dentina durante o procedimento restaurador com resina composta variando as fontes fotopolimerizadoras 
Alteração de temperatura na dentina durante o procedimento restaurador com resina composta variando as fontes fotopolimerizadoras

Dissertação apresentada à Faculdade de Odontologia de Ribeirão Preto da Universidade de São Paulo, para obtenção do Título de Mestre em Odontologia.

Área de Concentração: Odontologia Restauradora, opção: Dentística.

Orientadora: Prof $^{\mathrm{a}}$. Dr ${ }^{\mathrm{a}}$. Regina Guenka Palma Dibb 
AUTORIZO A REPRODUÇÃO E/OU DIVULGAÇÃO TOTAL OU PARCIAL DA PRESENTE OBRA, POR QUALQUER MEIO CONVENCIONAL OU ELETRÔNICO, PARA FINS DE ESTUDO E PESQUISA, DESDE QUE CITADA A FONTE.

\section{FICHA CATALOGRÁFICA}

Preparada pela Biblioteca Central do Campus Administrativo de Ribeirão Preto / USP

Savaris, Cristiane

Alteração de temperatura na dentina durante o procedimento restaurador com resina composta variando as fontes fotopolimerizadoras. Ribeirão Preto, 2008.

62 p. : il. ; $30 \mathrm{~cm}$

Dissertação (Mestrado), apresentada à Faculdade de Odontologia de Ribeirão Preto/USP. Área de concentração: Odontologia Restauradora.

Orientadora: Palma-Dibb, Regina Guenka.

1. Temperatura. 2. Fotopolimerização. 3. Resina composta. 
Cristiane Savaris

Influência de fontes fotopolimerizadoras no aumento de temperatura pulpar durante o procedimento restaurador com resina composta

Dissertação apresentada à Faculdade de Odontologia de Ribeirão Preto da Universidade de São Paulo, para obtenção do Título de Mestre em Odontologia.

Área de Concentração: Odontologia Restauradora, opção: Dentística.

Aprovada em:

Banca Examinadora

Prof. Dr.

Instituição:

Assinatura:

Prof. Dr.

Instituição:

Assinatura:

Prof. Dr.

Instituição:

Assinatura: 


\section{DEDICATÓRIA}

\section{Aos meus pais Doris e Juvelino}

Por não medirem esforços em proporcionar sempre o melhor a seus filhos, dando exemplos de honestidade, trabalho, respeito e união. Sem seus valiosos ensinamentos, sem o apoio incondicional em todas as etapas da minha vida, esta conquista não seria possível. Não há palavras ou gestos para agradecer e retribuir tudo o que fizeram e fazem por mim. Os seus gestos de carinho perfumaram a minha vida. A vocês pessoas que mais amo e admiro o meu eterno amor!

À minha amada tia Madalena

A você que me incentivou, acreditou e sempre se fez presente na minha vida, pois as minhas alegrias também são suas e estão marcadas pelo seu estímulo, seu carinho, sua dedicação e seu amor. E ainda hoje, mesmo já grandinha, encontro em minhas conquistas a sua constante presença!

\section{Aos meus irmãos Elisson, Bruno, Roberto e Larissa}

Meus "maninhos" que sempre estiveram comigo a todo o momento, a cada passo dado e escutaram as mais mirabolantes histórias da minha fase de deslumbramento. Acompanharam todo o meu amadurecimento pessoal e profissional. Obrigada pelo carinho, compreensão, apoio, exemplo e sem dúvida, pela amizade ilimitada que nos une!

\section{Ao meu namorado Pedro}

Olhando para os teus olhos, descobri o sentido profundo que se oculta em mim. Deixando-me cativar pelo seu contagiante sorriso, aprendi também a sorrir. Obrigada por estar ao meu lado, me apoiando, por completar a minha vida, por todos os momentos de alegria que passamos e pelos que ainda virão!

À minha sobrinha e afilhada Sophia, que com seu lindo sorrisinho inundou a nossa família de alegria! Você é uma bênção para nós! 


\title{
AGRADECIMENTOS ESPECIAIS
}

\section{À Deus}

Senhor eu te dou graças pelas pessoas maravilhosas que pusestes em meu caminho, sei que é através da presença delas que tu ficas ao meu lado, sempre zelando por mim. Louvado seja porque Te revelas em gestos tão humanos que posso Te sentir sempre perto de mim.

\begin{abstract}
À Profa. Dra. Regina Guenka Palma Dibb
Por acreditar e confiar na minha capacidade para realizar esta caminhada, pela disponibilidade em orientar-me e por ter possibilitado compartilhar do seu saber e experiência. Por todo conhecimento e responsabilidade transmitidos como pessoa e profissional.
\end{abstract}

À Super Michelle Alexandra Chinelatti

Que prontamente se dispôs a participar deste trabalho, contribuindo construtivamente com conhecimento e disponibilidade. Pela sua amizade, estímulo e exemplo de dedicação à pesquisa científica.

\section{Ao Prof. Dr. Jesus Djalma Pécora}

Obrigada por toda orientação que me dedicou, não medindo esforços para que este momento se tornasse possível e, principalmente pelo exemplo de profissional e pesquisador que me norteará ao longo de toda a minha vida. 


\section{AGRADECIMENTOS}

À Faculdade de Odontologia de Ribeirão Preto da Universidade de São Paulo, através de seu Diretor, Prof. Dr. Osvaldo Luiz Bezzon.

Ao Departamento de Odontologia Restauradora, na pessoa do Prof. Dr. Jesus Djalma Pécora.

À Coordenação do Curso de Pós-Graduação em Odontologia Restauradora da Faculdade de Odontologia de Ribeirão Preto da Universidade de São Paulo, na pessoa do Prof. Dr. Manoel Damião de Sousa Neto.

Aos Profs. Drs. Jesus Djalma Pécora e Manoel Damião de Sousa Neto, pela participação como membros da banca examinadora em minha qualificação.

Aos Professores do Departamento de Odontologia Restauradora da Faculdade de Odontologia de Ribeirão Preto da Universidade de São Paulo.

Ao Prof. Dr. Luciano Bachmann e ao aluno Fabrício Augusto de Lima do Departamento de Física e Matemática da Faculdade de Filosofia Ciências e Letras de Ribeirão Preto da Universidade de São Paulo, pelo auxílio na execução dos procedimentos com o equipamento e o software para análise da temperatura.

Às amigas Alessandra, Aline, Danielle, Ju Ciccone, Ju Faraoni e Vivian 
“Cada um que passa em nossa vida passa sozinho. Porque cada pessoa é única para nós, e nenhuma substitui a outra. Cada um que passa em nossa vida passa sozinho, mas não vai só. Levam um pouco de si mesmos. Há os que levam muito e os que levam pouco, mas não há os que não levam nada. Esta é a mais bela realidade da vida. A prova tremenda de que cada um é importante e que ninguém se aproxima do outro por acaso."

Saint Exupery

Aos colegas de mestrado César, Daniel, Fernando, Francisco e Walter, pela amizade e intercâmbio de conhecimentos.

Ao secretário do Curso de Pós-Graduação em Odontologia Restauradora da Faculdade de Odontologia de Ribeirão Preto da Universidade de São Paulo, Carlos.

Aos técnicos do laboratório de Pesquisa em Dentística da Faculdade de Odontologia de Ribeirão Preto da Universidade de São Paulo, Patrícia Marchi e Reginaldo Santana.

Às secretárias do Departamento de Odontologia Restauradora da Faculdade de Odontologia de Ribeirão Preto da Universidade de São Paulo, Amália e Maria Isabel.

Às funcionárias do Departamento de Odontologia Restauradora da Faculdade de Odontologia de Ribeirão Preto da Universidade de São Paulo, Luisa e Rosângela.

Às funcionárias da Seção de Pós-Graduação da Faculdade de Odontologia de Ribeirão Preto da Universidade de São Paulo, Isabel e Regiane.

À CAPES, pelo financiamento da bolsa de mestrado

A todos que, de alguma forma, colaboraram para que este trabalho fosse realizado, meu agradecimento muito especial. 


\section{RESUMO}

\section{SAVARIS C. Alteração de temperatura na dentina durante o procedimento restaurador}

com resina composta variando as fontes fotopolimerizadoras. 2008. 62 p. Dissertação de Mestrado - Faculdade de Odontologia de Ribeirão Preto, Universidade de São Paulo, Ribeirão Preto, 2008.

O objetivo deste estudo foi avaliar a influência do tipo de fonte luminosa e da espessura do remanescente dental no aumento de temperatura na câmara pulpar durante a fotopolimerização de uma resina composta. Métodos: Utilizaram-se 96 fragmentos $(6 \times 7 \mathrm{~mm})$ obtidos a partir das superfícies vestibulares de incisivos bovinos que foram divididos em 2 grupos e 4 subgrupos ( $\mathrm{n}=12$ ), de acordo com a fonte de luz (LED e luz halógena) e da espessura de remanescente dental $(3,5 \mathrm{~mm} ; 3,0 \mathrm{~mm} ; 2,0 \mathrm{~mm}$ e $1,0 \mathrm{~mm})$. Foram preparadas cavidades de classe I ( $3 \times 2 \mathrm{~mm})$, deixando a espessura dos respectivos remanescentes dentais, e restauradas com uma resina composta. A variação de temperatura foi captada por termopares posicionados na dentina do teto da câmara pulpar durante a fotopolimerização (20s) do agente adesivo e de cada incremento de resina composta. Foi considerado o maior valor de temperatura registrado durante todo o procedimento restaurador e também durante a fotopolimerização de cada incremento de resina composta. Os dados foram analisados usando ANOVA e Teste de Fisher $(\alpha=5 \%)$. Resultados: O LED promoveu maiores $(p<0,05)$ valores de temperatura do que a luz halógena; os valores mais baixos de temperatura foram $(\mathrm{p}<0,05)$ para 3,5 $\mathrm{mm}$ de espessura e os maiores para os remanescentes de $1 \mathrm{~mm}$ de espessura de remanescente dental; não houve diferença significativa $(p>0,05)$ entre as espessuras de 2,0 mm e 3,0 mm. O aumento de temperatura não foi significativo entre a luz LED e halógena durante a fotopolimerização do agente adesivo, no entanto, os valores registrados no decurso 
de cada compósito incremento fotopolimerizado foram estatisticamente superiores para a fonte de luz LED. Conclusões: o aumento de temperatura foi dependente do tipo de fonte de luz, da espessura do remanescente dental e do número de sucessivas fotoativações.

Palavras-chave: temperatura, fotopolimerização, resina composta, dentina. 


\begin{abstract}
SAVARIS C. Temperature alteration in dentin according to the photopolymerization source during composite-resin restorations. 2008. 62 p. Dissertation (Master's degree) School of Dentistry of Ribeirão Preto, University of São Paulo, Ribeirão Preto, 2008.

Objective: to evaluate the influence of the type of light source and the thickness of remaining dentin on temperature rise in the roof of the pulp chamber during photopolymerization of a composite resin. Methods: 96 tooth fragments $(6 \times 7 \mathrm{~mm})$ obtained from buccal surfaces of bovine incisors were randomly divided into 2 groups and 4 subgroups $(n=12)$ according to the light source (LED and halogen light) and the thickness of remaining tooth structure $(3.5 \mathrm{~mm}$, $3.0 \mathrm{~mm}, 2.0 \mathrm{~mm}$ and $1.0 \mathrm{~mm})$. Class I cavities $(3 \times 2 \mathrm{~mm})$ were prepared, leaving the respective thickness of remaining tooth structure, and restored with a composite resin. Temperature rises were obtained by thermocouples positioned in dentin in the roof of the pulp chamber during photopolymerization (20s) of the adhesive agent and each composite resin increment. It was considered the highest temperature rise registered during the whole restorative procedure and also during photopolymerization of each composite resin increment. Data were analyzed using ANOVA and Fisher's Test $(\alpha=5 \%)$. Results: LED promoted higher $(\mathrm{p}<0.05)$ temperature values than halogen light; temperature values were the lowest $(p<0.05)$ for 3.5mm-thick remaining and the highest for 1-mm-thick remaining; there was no difference $(p>0.05)$ between thicknesses of $2 \mathrm{~mm}$ and $3 \mathrm{~mm}$. Mean temperature rises were not significant between LED and halogen light during adhesive photopolymerization, however, values registered during each composite increment photopolymerization were statistically superior for LED unit. Conclusions: temperature rise was dependent on the type of light source, on the thickness of remaining tooth structure, and on the number of successive photoactivations.
\end{abstract}

Key words: temperature, fotopolimerization, composite-resin, dentin. 


\section{SUMÁRIO}

1. INTRODUÇÃO

2. PROPOSIÇÃO

3. MATERIAL E MÉTODO

4. RESULTADOS 32

5. DISCUSSÃO 41

6. CONCLUSÕES

REFERÊNCIAS BIBLIOGRÁFICAS 52

ANEXO 61 


\section{Introdução}




\section{INTRODUÇão}

A busca por excelência em Odontologia juntamente com a grande procura por procedimentos estéticos pelos pacientes tem direcionado estudos para aprimorar equipamentos e técnicas de fotopolimerização, bem como melhorias no comportamento dos materiais restauradores (AWLIYA, 2007).

Os primeiros compósitos odontológicos restauradores à base de Bis-GMA foram introduzidos em meados da década de 60, contudo apresentavam resultados clínicos insatisfatórios (BOWEN, 1963). Na tentativa de melhorar o material e torná-lo mais versátil surgiram as resinas fotoativadas por luz ultravioleta (BOWEN, 1963; LEE; ORLOWSKI; ROGERS, 1976; De LANGE; BAUSCH; DAVIDSON, 1980; ANUSAVICE, 1998), que apresentavam o controle total do tempo, menor inclusão de ar dentro do corpo da restauração, no entanto, proporcionavam propriedades físicas e mecânicas inadequadas devido ao baixo grau de conversão ocorrido pela limitação da penetração da luz no compósito, associado a isso os riscos causados aos tecidos vivos por este tipo de radiação (PEUTZFELDT; SAHAFI; ASMUSSEN, 2000; SAHAFI; PEUTZFELDT;. ASMUSSEN, 2001).

Assim, posteriormente surgiram as resinas fotoativadas por luz visível que permitiam a polimerização do compósito em maiores profundidades com menores tempos de exposição, além de proporcionarem mais segurança (RUYTER; ØYSÆD, 1982; PEUTZFELDT; SAHAFI; ASMUSSEN, 2000). A modificação principal destes materiais foi a adição de fotoiniciadores sensíveis à luz visível. O uso do sistema ativador/iniciador baseado na 
combinação canforoquinona/amina terciária foi adotado, sendo o mais utilizado atualmente (ANUSAVICE, 1998; ALTHOFF; HARTUNG, 2000; STANSBURY, 2000). A luz visível utilizada para fotoativação dos compósitos restauradores abrange a zona azul do espectro luminoso, com comprimento de onda entre 410 e 550 nm (IRIE; SUZUKI; WATTS, 2002).

A disponibilidade de sistemas resinosos ativados por luz levou ao desenvolvimento de uma variedade de tecnologias para produzir a luz necessária para a polimerização destes, como por exemplo: luz halógena de quartzo-tungstênio (QTH), e a luz emitida por diodo (LED) (UHL; MILLS; JANDT, 2003; MARTINS; CAVALCANTI; RODE, 2006).

Os aparelhos mais tradicionais e mais utilizados que emitem luz visível são compostos de lâmpadas de quartzo-tungstênio-halogênio. (BOUILLAGUET et al., 2005; RATIH; PALAMARA; MESSER, 2007). Estas lâmpadas consistem de um filamento de tungstênio protegido por uma cápsula de quartzo com gases inertes e conectado a um eletrodo, o qual, permitindo o fluxo de corrente elétrica, gera luz e calor (RUEGGEBERG, 1999; TAHER et al., 2008). Este filamento é submetido a altas temperaturas, produzindo uma luz com energia de amplo espectro, inclusive englobando faixa da radiação infravermelha, a qual é responsável pela geração de calor (TAHER et al., 2008). A luz branca emitida passa por filtros específicos para selecionar apenas a região azul do espectro para a fotoativação do compósito odontológico (BURGESS et al., 2002). Este tipo de lâmpada possui vida útil média de 50 horas, porém com o tempo, os componentes deste aparelho apresentam degradação, diminuindo a potência da energia emitida e reduzindo a efetividade da fotoativação (BURGESS et al., 2002).

Devido às desvantagens apresentadas pelo equipamento de luz halógena, novas tecnologias foram desenvolvidas, entre elas o LED (Light emitting diode) (MILLS, 1995), em que utiliza diodos emissores de luz com a finalidade de minimizar o calor gerado pela fotoativação com a luz halógena (STAHL et al., 2000). O LED é constituído de materiais 
semicondutores (nitrito de gálio), que determinam o comprimento de onda entre 450 a 490nm com um pico de 470nm (BURGESS et al., 2002), que está relacionado com a taxa de absorção do espectro da canforoquinona (LEONARD et al., 2002). Desse modo, os aparelhos de LED não trabalham com comprimentos de ondas da faixa infravermelho, requerem menos energia para operar (UHL; MILLS; JANDT, 2003), gerando pouco calor (LEONARD et al., 2002). Este equipamento possui uma grande vantagem, apresentam longo tempo de vida útil (acima de 10.000 horas), com pouca degradação com o seu uso, não ocorrendo variação na sua potência e não necessitam de filtros especiais devido ao estreito espectro de comprimento de onda emitido. (CAUGHMAN; RUEGGEBERG, 2002). Os primeiros LEDs apresentavam limitações devido a baixa potência, como a insuficiente absorção de energia para converter as moléculas de resina em cadeias poliméricas. No entanto, com o desenvolvimento da tecnologia, as unidades de fotopolimerização LEDs passaram por uma segunda geração e atualmente, já se encontram na terceira geração com potências mais elevadas (WIGGINGS et al., 2008).

A utilização de alta intensidade produzida pelas unidades fotoativadoras foi sugerida para efetuar uma polimerização mais rápida (WIGGINGS et al., 2008). Durante muito tempo, a utilização de alta intensidade de luz para a fotoativação foi preconizada como ideal para polimerização dos compósitos resinosos, sendo associada à adequada profundidade de polimerização e também a obtenção de propriedades físicas e mecânicas desejáveis (MEHL; HICKEL; KUNZELMANN, 1997). Entretanto, maior velocidade de polimerização pode produzir menor grau de conversão em todas as profundidades do material, quando comparado com a luz convencional (TARLE et al.,2002).

De maneira geral, o processo de polimerização dos compósitos denota ser mais dependente da densidade total de energia disponível no momento da fotoativação do que da intensidade da luz propriamente dita (MIYAZAKI et al., 1996; SAKAGUCHI; BERGE, 
1998). Portanto, grau de conversão aceitável pode ser conseguido nos compósitos utilizandose baixa intensidade de luz por um tempo mais prolongado ou, até mesmo, utilizando intensidades variáveis por tempo de exposição determinado (UNO; ASMUSSEN, 1991; FEILZER et al., 1995; SAKAGUCHI; BERGE,1998).

Apesar da grande vantagem da polimerização da resina composta com equipamentos de emissão de luz, este método possui o efeito indesejado de aquecer os tecidos dentais, seja tanto por difusão do calor, como diretamente da emissão de energia (HUSSEY; BIAGIONI; LAMEY, 1995; YAP; LOW; ONG, 2000). Atualmente diversos estudos (MASUTANI et al., 1988; HANNIG; BOTT, 1999; ALTINTAS et al., 2008) têm avaliado o efeito do aumento de temperatura, gerado durante o processo de fotopolimerização das resinas compostas, no tecido pulpar. A quantificação do trauma térmico tolerado pelo tecido pulpar é desconhecida (BALDISSARA; CATAPONO; SCOTTI, 1997; STEWARDSON et al., 2004; MILLEN et al., 2007) pois a polpa é protegida pelo esmalte e dentina. Possíveis injúrias térmicas sofridas pelo tecido pulpar são amenizadas principalmente pelo substrato dentinário, por possuir baixa condutibilidade térmica (BROWN; DEWEY; JACOBS, 1970). Contudo, em função da morfologia dentinária, deve-se considerar a presença de prolongamentos odontoblásticos no interior dos túbulos dentinários que fazem a comunicação direta com o tecido pulpar (LINSUWANONT; PALAMARA; MESSER, 2007). Assim, haverá um aumento significativo na difusão térmica quando da diminuição da espessura dentinária devido a maior densidade e diâmetro tubular, facilitando a ocorrência de injúrias pulpares (HUSSEY; BIAGIONI; LAMEY, 1995; LINSUWANONT; PALAMARA; MESSER, 2007).

A polpa dental é um tecido conjuntivo altamente especializado, ricamente inervado, vascularizado e responsável pela vitalidade do órgão dental (HUSSEY, BIAGIONI, LAMEY, 1995). Composta por células mesenquimais indiferenciadas, odontoblastos, células imunocompetentes incluindo células dendríticas (KITAMURA, et al., 2005) que podem sofrer 
com o aquecimento proporcionado pelo preparo cavitário e processo restaurador, devido à extraordinária quantidade de calor que pode ser induzido pela preparação das cavidades ou pela reação exotérmica, que ocorre na reação de polimerização dos materiais forradores (TUNC, 2007) e restauradores (McCABE; WILSON, 1980; ANUSAVICE, 1998) quanto pela energia absorvida durante a irradiação da luz fotoativadora (McCABE, 1985; SHORTALL; HARRINGTON, 1998; TUNC, 2007), podendo levar a lesões inflamatórias irreversíveis a polpa (LISANTI; ZANDER, 1952; SHORTALL; HARRINGTON, 1998; TAHER et al, 2008).

Contudo, existem poucos estudos que determinam quanto de aumento de temperatura pode ser suportado pelo órgão pulpar, tendo o estudo clássico de Zach e Cohen (1965), observado in vivo em dentes de Macacos Rhesus submetidos a diferentes aumentos de temperatura de $2,2^{\circ} \mathrm{C}, 5,5^{\circ} \mathrm{C}, 11,1^{\circ} \mathrm{C}$ e $16,6^{\circ} \mathrm{C}$ obtidos pelo contado com ferro de soldagem. $\mathrm{O}$ aumento de temperatura de $2,2^{\circ} \mathrm{C}$, no intervalo de 2 dias, produziu mínima alteração histológica que não foi mais verificada nos outros intervalos de tempo, porém verificaram que alterações pulpares irreversíveis podem ser geradas pela elevação da temperatura. De modo que, com um aumento de temperatura de $5,5^{\circ} \mathrm{C}$ ocorreram alterações morfológicas nas células, sendo que em $15 \%$ dos espécimes houve necrose pulpar, observada somente no intervalo de 91 dias. Para o aumento de $11,1^{\circ} \mathrm{C}$ no intervalo de 2 dias houve completa destruição dos odontoblastos, sendo que nos demais intervalos, foram encontrados abscessos oriundos da necrose pulpar, em $60 \%$ dos espécimes. No aumento de $16,6^{\circ} \mathrm{C}$ no intervalo de 2 dias a polpa já havia necrosado, totalizando $100 \%$ dos espécimes. Os autores concluíram que aumentos de temperatura acima de $5,5^{\circ} \mathrm{C}$ podem levar a alterações histológicas significativas na polpa levando inclusive a necrose pulpar.

Provavelmente um dos maiores responsáveis pelo aumento de temperatura intra-pulpar é o processo de fotopolimerização dos materiais fotoativados (McCABE, 1985; LLOYD; 
JOSHI; McGLYNN, 1986; MASUTANI et al., 1988), principalmente devido ao aumento da intensidade da luz dos equipamentos modernos, que promovem uma elevação da temperatura durante a polimerização, devido à maior energia de radiação fornecida pela unidade fotoativadora (HANSEN; ASMUSSEN, 1993; Al-QUDAH et al., 2007).

Estudos demonstraram que a exotermia é quase instantânea, ocorrendo assim que a fonte de luz é ativada e aumentando até por aproximadamente 30 segundos antes do nivelamento (HUSSEY; BIAGIONI; LAMEY, 1995). As mudanças de temperatura revelaram larga variação de valores, entre $0,05^{\circ} \mathrm{C}$ nos primeiros 15 segundos e $11,7^{\circ} \mathrm{C}$ no mesmo período. A diferença pode ser explicada pela relação da ponta do fotoativador com o compósito. Quando a ponta foi colocada no ângulo exato da maior área de material, a reação exotérmica foi mais rápida e maior. Quanto menor o preparo, menor a quantidade de material e a exotermia será menos intensa. Assim, um fator decisivo para a variação de temperatura é a energia absorvida durante a irradiação (DANESH et al., 2004), seguida do processo exotérmico da reação de polimerização das resinas compostas (HOFMANN et al., 2004; SINGH; MOHAN; LAKSHMINARAYANAN, 2005).

Procurando formas de diminuir a temperatura gerada durante a fotoativação de compósitos odontológicos, Uhl, Mills e Jandt (2003) verificaram que uma quantidade reduzida de resina composta e/ou uma unidade de baixa intensidade de luz deveriam ser necessárias para reduzir o estresse térmico sobre os tecidos pulpares. Com o mesmo objetivo, Masutami et al. (1988), recomendaram a técnica incremental. Entretanto, Lloyd, Joshi e Mcglynn (1986) e Shortall e Harrington (1998) relataram que a temperatura aumentava com a diminuição da espessura do compósito, ou seja, a elevação da temperatura foi maior quando a luz foi aplicada sobre a cavidade vazia tendo um menor aumento de temperatura com a presença do compósito. Outro fator a ser considerado é que a variação de temperatura durante a fotopolimerização pode ser influenciada principalmente pela espessura do remanescente 
dental (LONEY; PRICE, 2001, AGUIAR et al., 2005) e pela permeabilidade dos túbulos dentinários (SHORTALL; HARRINGTON, 1998).

Contudo, para uma adequada fotopolimerização de uma resina composta é necessário uma dose certa de intensidade de luz (YAP; LOW; ONG, 2000), tempo (KNEZEVIĆ et al., 2001) e comprimento de onda adequado (KNEZEVIĆ et al., 2001). Sabe-se que a alta intensidade de luz promove altos valores em termos de grau de conversão, resultando em melhores propriedades físicas e mecânicas dos materiais restauradores (TARLE et al., 2006), entretanto proporciona maiores aumentos de temperatura (OZTURK et al., 2004; SHORTALL; PALIN; BURTSCHER, 2008).

Diante do exposto, torna-se necessário enfatizar as vantagens oferecidas pelas diferentes fontes fotopolimerizadoras, porém, sem que tais procedimentos ocasionem alterações significativas nas propriedades biológicas dos tecidos dentais e nas propriedades mecânicas do material restaurador. Por esses motivos considera-se importante a avaliação dos meios de fotopolimerização para que os mesmos sejam indicados de acordo com as necessidades do procedimento restaurador a ser realizado, levando-se em conta os fatores relativos à espessura do remanescente dental do preparo cavitário bem como o acúmulo de calor gerado durante todo o processo restaurador. 
2. Proposição 


\section{Proposição}

O presente estudo propôs-se a avaliar in vitro a influência de duas fontes de luz (LED, halógena) na variação de temperatura na dentina do teto da câmara pulpar durante a restauração em incrementos com sistema resinoso em cavidades com diferentes espessuras de remanescente dental. 
3. Materiale Método 


\section{Material e Método}

\section{Delineamento experimental}

No presente trabalho os fatores de estudo foram: equipamento de fotopolimerização (fonte de luz) em dois níveis: luz halógena e luz emitida por diodo (LED) e espessura do remanescente dental em quatro níveis: $3,5 \mathrm{~mm}(0,5 \mathrm{~mm}$ de esmalte e $3,0 \mathrm{~mm}$ de dentina), 3,0 $\mathrm{mm}, 2,0 \mathrm{~mm}$ e 1,0 $\mathrm{mm}$ de dentina. A amostra do experimento foi composta de 96 fragmentos de dentes bovinos divididos aleatoriamente em 2 grupos e 4 subgrupos, pela combinação dos níveis dos fatores de estudo, com doze repetições por grupo/subgrupo experimental (Tabela 1). Os três princípios básicos da experimentação - aleatorização, repetição e blocagem (MONTGOMERY, 2001) - foram respeitados.

Tabela 1 - Distribuição dos grupos/subgrupos experimentais

\begin{tabular}{ccccc}
\hline Remanescente & $\begin{array}{c}\mathbf{3 , 5} \mathbf{~ m m} \\
(\mathbf{1})\end{array}$ & $\begin{array}{c}\mathbf{3 , 0} \mathbf{~ m m} \\
(\mathbf{2})\end{array}$ & $\begin{array}{c}\mathbf{2 , 0} \mathbf{~ m m} \\
\mathbf{( 3 )}\end{array}$ & $\begin{array}{c}\mathbf{1 , 0} \mathbf{~ m m} \\
\text { (3) }\end{array}$ \\
\hline \hline Ultralume LED 5 (A) & A1 & A2 & A3 & A4 \\
Jet lite 4000 Plus (B) & B1 & B2 & B3 & B4 \\
\hline \hline
\end{tabular}

As variáveis de resposta quantitativas foram: a variação de temperatura $(\Delta T)$, em graus Celsius $\left({ }^{\circ} \mathrm{C}\right)$, registrada durante todo o procedimento restaurador; a variação de temperatura $(\Delta \mathrm{t})$, em graus Celsius $\left({ }^{\circ} \mathrm{C}\right)$, ocorrida durante a fotoativação de cada camada (incremento) do material restaurador. 


\section{Seleção dos dentes}

Incisivos centrais bovinos hígidos foram limpos e examinados em lupa estereoscópica com 10x de aumento. Os dentes que apresentavam anomalias de estruturas foram descartados. Deste modo, foram selecionados 96 incisivos e mantidos sob refrigeração $\left(4^{\circ} \mathrm{C}\right)$ em solução aquosa de timol a $0,1 \%$.

\section{Obtenção dos espécimes e confecção das cavidades}

A raiz, o terço cervical, incisal e a face lingual dos dentes foram removidos através de cortes perpendiculares ao longo eixo do dente com disco diamantado (IsoMet ${ }^{1000}$ Buehler) acoplado à cortadeira de precisão (IsoMet®1000 - Buehler), sob refrigeração constante (Figura 1A). O remanescente pulpar foi removido após o corte. Os remanescentes das coroas dentais foram fixados individualmente com cera para escultura em placas de acrílico (Figura 1B) para facilitar a realização de cortes nos sentidos mésio-distal e cérvicoincisal nas faces vestibulares (Figura 1C), obtendo-se espécimes com dimensões de 7x6 mm, respectivamente (Figura 1D). Os espécimes foram divididos aleatoriamente em 2 grupos (A e B) e 4 subgrupos ( 1 a 4) de acordo com a fonte de luz e a espessura do remanescente dental. Em cada fragmento foram delimitadas as dimensões do preparo cavitário $(3 \times 2 \mathrm{~mm})$ (Figura 1E). Os preparos foram confeccionados com broca carbide \#245 em alta-rotação sob refrigeração constante, sendo descartada a cada 6 preparos cavitários realizados. A profundidade do preparo foi suficiente para determinar a espessura de remanescente dental correspondente ao subgrupo: $3,5 \mathrm{~mm}(0,5 \mathrm{~mm}$ de esmalte e 3,0 $\mathrm{mm}$ de dentina), 3,0 $\mathrm{mm}, 2,0$ $\mathrm{mm}$ e $1,0 \mathrm{~mm}$ de dentina. 

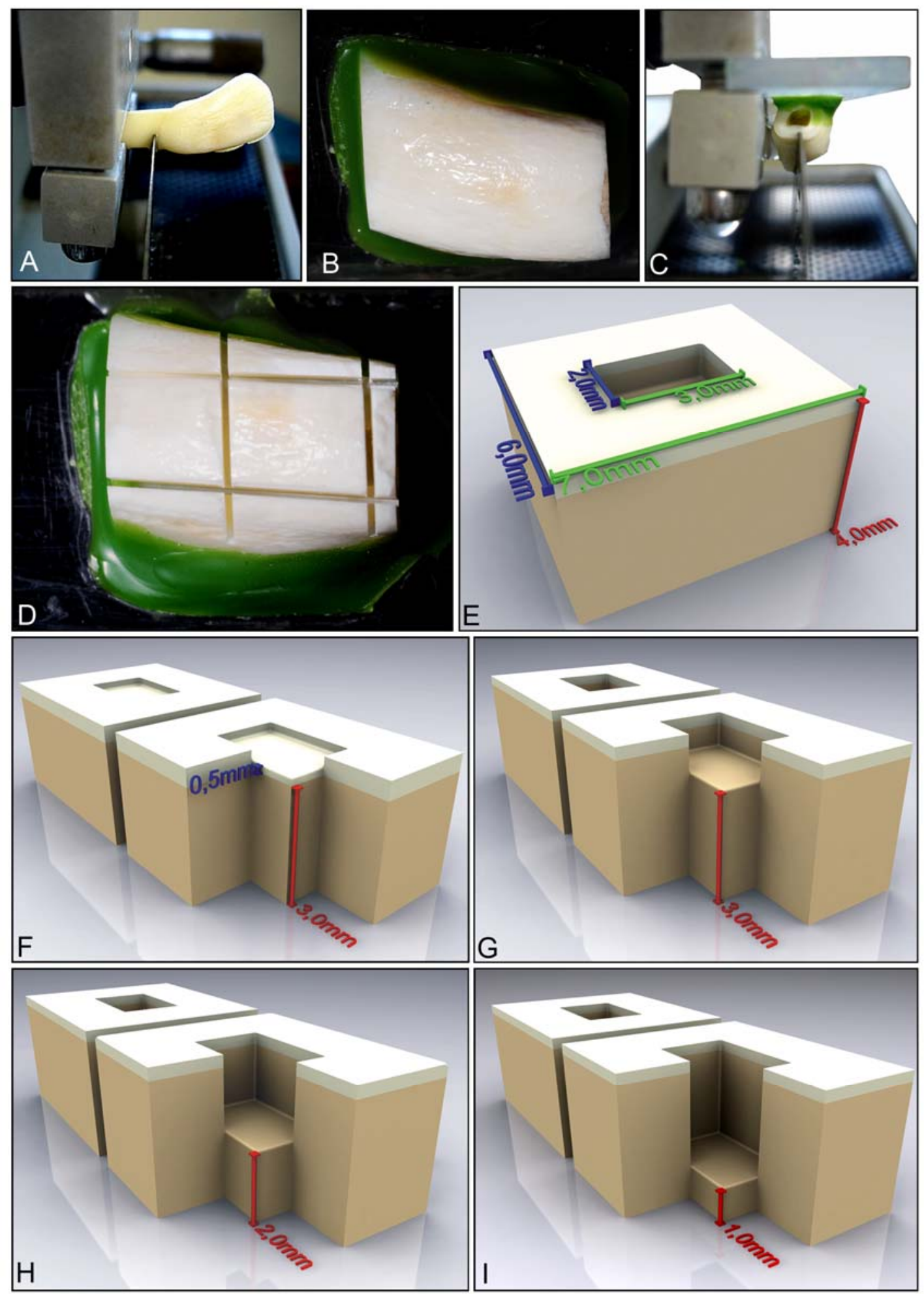

Figura 1. Obtenção dos espécimes e confecção das cavidades: A- secção das raízes; Bremanescente das coroas fixadas em placas de acrílico; C- realização dos cortes nas faces vestibulares; D- obtenção do espécime; E- preparo cavitário; F- representação esquemática dos espécimes com $3,5 \mathrm{~mm}$ de remanescente; G- representação esquemática dos espécimes com 3,0 mm de remanescente; H- representação esquemática dos espécimes com 2,0 $\mathrm{mm}$ de remanescente; I- representação esquemática dos espécimes com 1,0 $\mathrm{mm}$ de remanescente. 
Sendo assim, tomou-se o cuidado de padronizar tanto o remanescente quanto a profundidade, de modo que para o remanescente de $3,5 \mathrm{~mm}$ a profundidade do preparo foi de 0,5 $\mathrm{mm}$ em esmalte, para o remanescente de 3,0 $\mathrm{mm}$ a profundidade foi de 1,0 $\mathrm{mm}$, para o remanescente de 2,0 $\mathrm{mm}$ a profundidade foi de 2,0 $\mathrm{mm}$ e para o remanescente de $1,0 \mathrm{~mm}$ a profundidade foi de 3,0 mm (Figuras $1 \mathrm{~F}$ a 1I). A profundidade de cada preparo cavitário foi determinada utilizando-se um especímetro (BioArt/ São Carlos, Brasil).

$\mathrm{Na}$ superfície correspondente ao teto da câmara pulpar de cada espécime foram confeccionados três nichos (um central e dois laterais) (Figura 2B) com broca carbide $1 / 2 \mathrm{em}$ baixa rotação, sendo descartada a cada 6 nichos realizados, para a colocação dos termosensores. Os termosensores laterais correspondem às paredes laterais (circundantes) do preparo e o central corresponde ao centro da cavidade. A localização exata de cada nicho foi guiada com o auxílio do especímetro (BioArt/ São Carlos, Brasil).

\section{Procedimento restaurador}

Previamente à realização das restaurações, cada fragmento foi fixado com cera de baixa fusão em uma placa acrílica que apresentava um orifício central de $10 \mathrm{~mm}$ de diâmetro para expor as superfícies do preparo cavitário (Figura 2A) e do teto da câmara pulpar (Figura 2B).

A cavidade foi condicionada com gel de ácido fosfórico 35\% (Scotch Etchand, 3M ESPE USA) - (Tabela 2), por 15 segundos, o qual foi removido com spray ar/água por 40 segundos. O excesso de água foi retirado com o auxílio de papel absorvente, deixando a superfície dental ligeiramente umedecida. Anteriormente à aplicação do agente adesivo, os filamentos termosensores (Termopares tipo $\mathrm{K}-$ Omega ${ }^{\circledR}$ Engineering Inc. USA) foram inseridos nos nichos preparados no teto da câmara pulpar com a utilização de uma pasta térmica a base de água (Figura 2C-2E) para aumentar o contato térmico do termopar com os 
espécimes. Uma camada do agente adesivo Single Bond (3M ESPE USA) - (Tabela 2) foi aplicada sobre todas as paredes do preparo cavitário, deixou-se por 15 segundos e aplicou-se uma segunda camada sendo o excesso do agente adesivo removido com a ponta do próprio pincel, e o material foi fotopolimerizado por 20 segundos utilizando a fonte de luz correspondente ao grupo que pertencia o espécime. As especificações de cada aparelho fotopolimerizador estão descritos na Tabela 3 (Figuras $2 \mathrm{~F}$ e 2G).

Tabela 2 - Especificações técnicas dos materiais restauradores utilizados.

\begin{tabular}{cccc}
\hline Material & Composição* & Fabricante \\
\hline \hline Agente condicionador & Scotch Etchant & $\begin{array}{c}\text { Ácido fosfórico 35\% água, } \\
\text { sílica coloidal, pigmento }\end{array}$ & 3M ESPE Paul. MN, USA \\
& Adper Single & Bis-GMA, HEMA, & \\
Sistema adesivo & copolímero do ácido & 3M ESPE \\
polialcenóico, etanol, água & St Paul. MN, USA \\
Resina composta & e fotoiniciadores & \\
microhíbrida & Filtek Z250 & UDMA, Bis-EMA, & 3M ESPE \\
& & inorgânicas de carga & St Paul. MN, USA
\end{tabular}

"Abreviações: Bis-GMA: Bisfenol A - di-glicidil, éter di-metacrilato; HEMA: 2-Hidroxi-etil metacrilato; UDMA: uretano di-metacrilato; Bis-HEMA: Bisfenol A - polietileno glicol di-eter, dimetacrilato; TEGDMA: trietileno glicol dimetacrilato.

Tabela 3 - Aparelhos fotopolimerizadores utilizados e suas respectivas especificações

\begin{tabular}{ccccc}
\hline \hline Marca comercial & Fabricante & Tipo de luz & $\begin{array}{c}\text { Comprimento } \\
\text { de onda }\end{array}$ & $\begin{array}{c}\text { Densidade de } \\
\text { potência }\end{array}$ \\
\hline \hline $\begin{array}{c}\text { Ultralume LED } \\
\mathbf{5}\end{array}$ & $\begin{array}{c}\text { Ultradent Products, } \\
\text { INC. South Jordan, } \\
\text { UT 84095, USA }\end{array}$ & LED & 370 a $500 \mathrm{~nm}$ & $940 \mathrm{~mW} / \mathrm{cm}^{2}$ \\
Jet lite 4000 Plus & $\begin{array}{c}\text { J.Morita USA INC 9 } \\
\text { Mason Irvine, CA } \\
92618 \text { USA }\end{array}$ & Halógena & 400 a $500 \mathrm{~nm}$ & $900 \mathrm{~mW} / \mathrm{cm}^{2}$ \\
\hline \hline
\end{tabular}



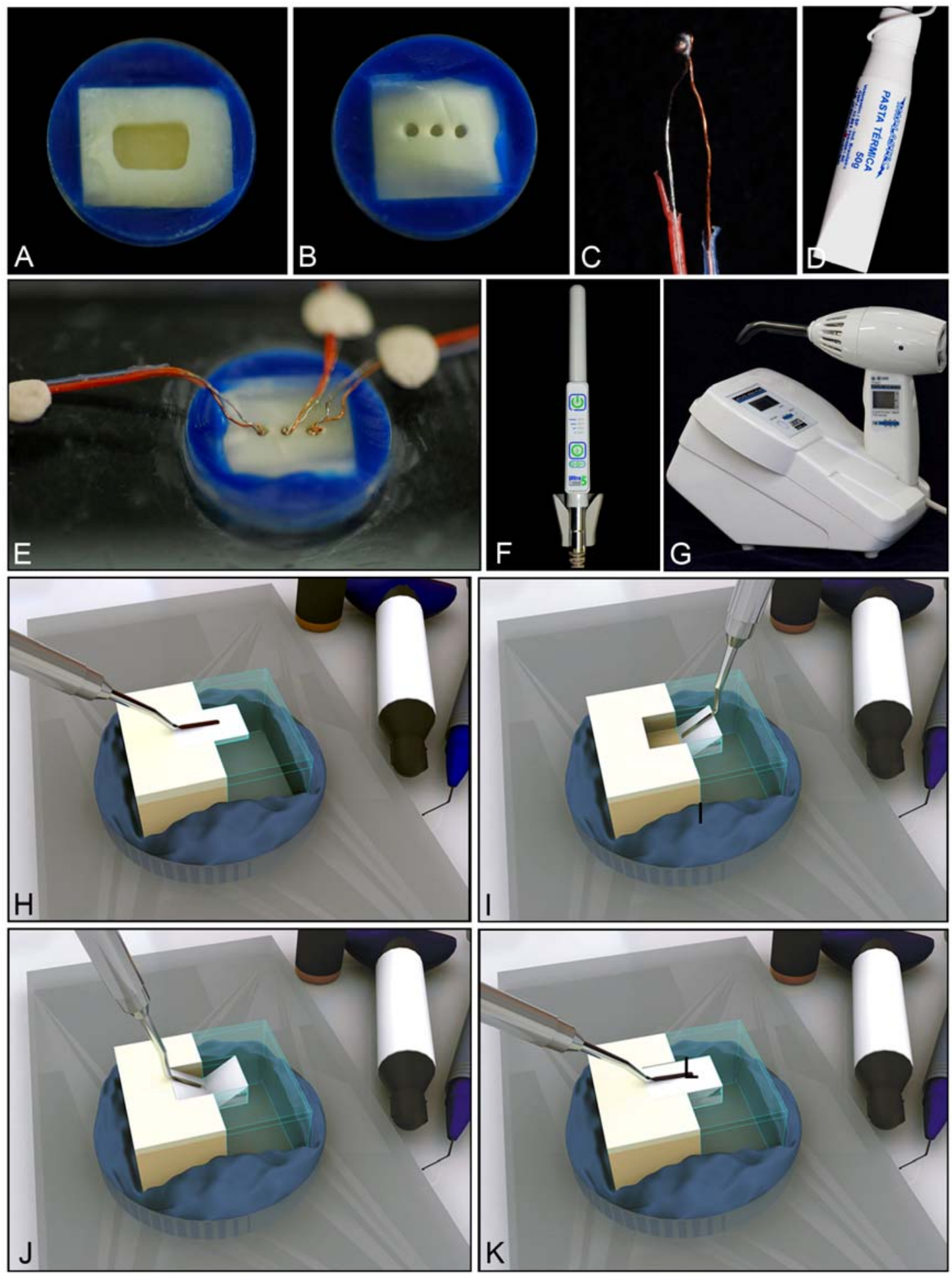

Figura 2. Procedimento restaurador: A- superfície do preparo cavitário; B- superfície do teto da câmara pulpar; C- ponto de solda (termopar tipo K); D- pasta térmica; E- termopares em posição; F- luz LED; G- luz Halógena; H- representação esquemática da inserção do incremento único; I- representação esquemática da inserção do primeiro incremento; Jrepresentação esquemática da inserção do segundo incremento; K- representação esquemática da inserção do terceiro incremento. 
As cavidades foram restauradas com resina composta microhíbrida (Filtek Z250, 3M ESPE, USA) - (Tabela 2), inserida com espátula, através das seguintes técnicas incrementais: as cavidades com profundidade de 0,5 mm (grupos/subgrupos A1 e B1) receberam apenas um incremento do material restaurador (Figura 2H), enquanto as demais cavidades (grupos/subgrupos A2, A3, A4, B2, B3 e B4) receberam três incrementos (dois oblíquos e um horizontal). O primeiro incremento oblíquo foi colocado nas paredes cervical e axial (Figura 2I), o segundo (oblíquo) nas paredes incisal e axial (Figura 2J) e o terceiro (horizontal) foi inserido unindo os dois anteriores (Figura 2K). Cada incremento de resina composta foi fotopolimerizado por 20 segundos utilizando a fonte de luz correspondente ao grupo que pertencia o espécime. Entre cada fotoativação foi aguardado um tempo de 30 segundos, sendo registrados os dados graficamente e numericamente ao longo de todo o procedimento restaurador.

\section{Avaliação da variação de temperatura}

A variação de temperatura foi registrada a partir do início da fotopolimerização do agente adesivo até o retorno a temperatura inicial após a fotopolimerização do último incremento da resina composta.

O equipamento de detecção de temperatura utilizado era composto por microtermopares do tipo K (Omega ${ }^{\circledR}$ Engineering Inc. USA) (Figura 3A) e uma placa de aquisição com 4 canais, com resolução de 24-Bits (USB-9211A, National Instruments ${ }^{\circledR}$ ) (Figura 3B). O equipamento foi calibrado com a participação do Instituto de Pesquisas Tecnológicas (IPT/SP) para precisão de $0,2^{\circ} \mathrm{C}$ e tempo de resposta de 0,6 s. Para aquisição dos dados foram utilizados os softwares Measurement \& Automation e VI Logger Lite fornecidos pelo fabricante da placa de aquisição. Este sistema estava interligado a um computador e foi configurado para fazer 3 leituras de temperatura a cada segundo (Figura 3C). 

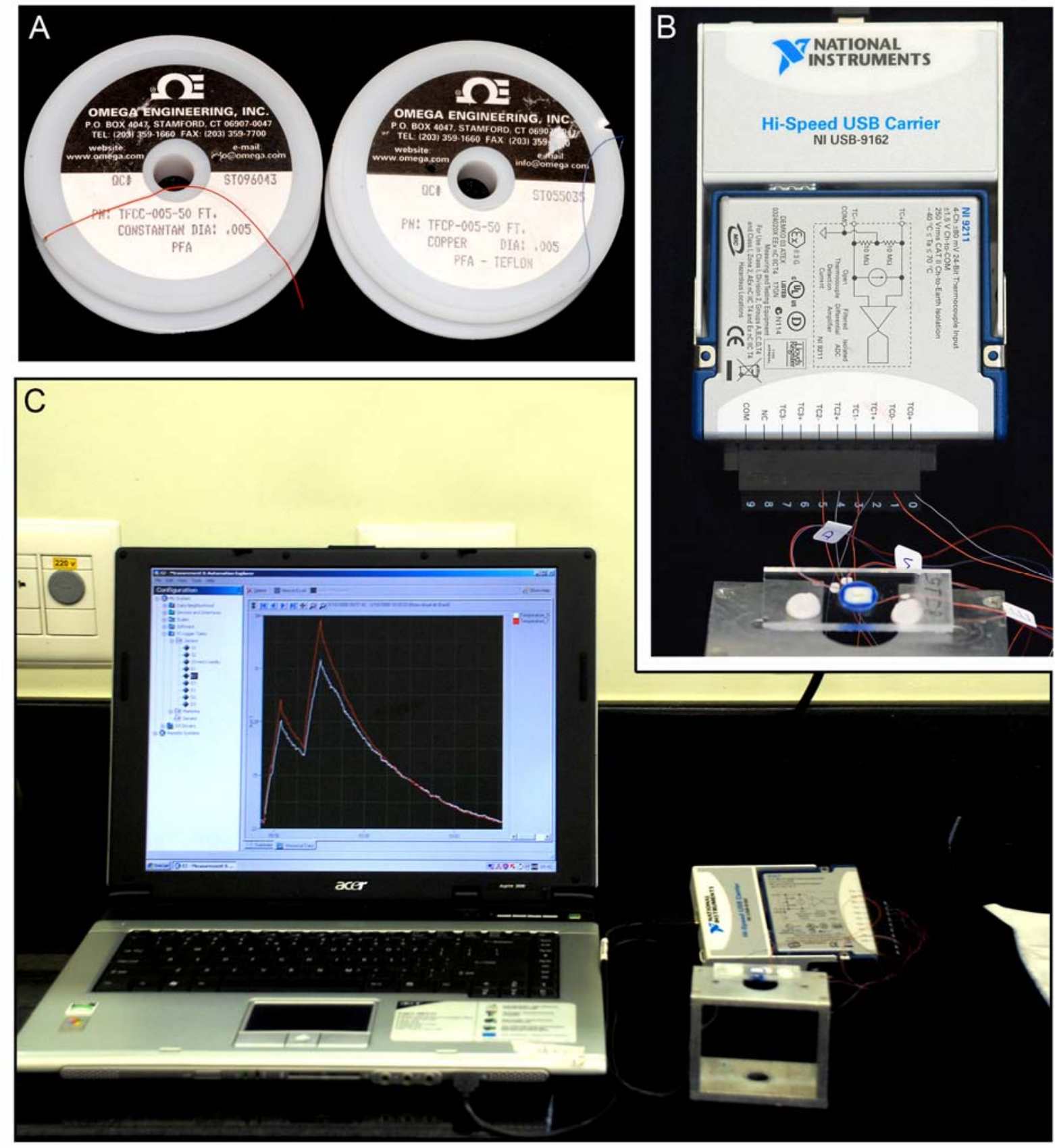

Figura 3. Avaliação da variação de temperatura: A- termopares tipo K; B- placa de aquisição USB; C- sistema para avaliação da variação de temperatura. 


\section{Análise dos dados}

Para análise dos dados, foi considerada a média dos valores dos três termopares de cada espécime.

Os valores obtidos para cada grupo/subgrupo foram tabulados de acordo com as variáveis de resposta:

- Variação total de temperatura atingida em graus Celsius $\left({ }^{\circ} \mathrm{C}\right)$ durante todo o procedimento restaurador $(\Delta \mathrm{T})$;

- Variação de temperatura atingida em graus Celsius $\left({ }^{\circ} \mathrm{C}\right)$ para cada camada (adesivo e incrementos de resina composta) do procedimento restaurador fotoativada $(\Delta \mathrm{t})$.

A distribuição dos dados foi verificada pelos testes de Levene e de Shapiro-Wilks, apresentando-se normal e homogênea. Desta forma, os dados foram individualmente submetidos à Análise de Variância (ANOVA), considerando o nível de significância de $\alpha=5 \%$, com dois fatores de variação (fonte de luz e remanescente dental). O teste de Fisher LSD foi aplicado para detectar eventuais diferenças significativas entre as médias. A análise estatística foi realizada utilizando o software de análise de dados Origin 8 (Origin Lab Data Analysis and Graphing Software. OriginLab Corporation - Northampton, MA 01060 USA). 
4. Resultados 


\section{Resultados}

\subsection{Variação de temperatura atingida durante todo o procedimento restaurador $(\Delta T)$}

$\mathrm{Na}$ análise dos dados observou-se que ocorreu diferença estatisticamente significante $(p<0,05)$ para o fator fonte de luz e para o fator remanescente dental. Na comparação entre os dois tipos de fonte de luz observou-se que o equipamento LED promoveu uma maior variação de temperatura do que com a luz halógena (Tabela 4).

Tabela 4 - Variação de temperatura média $\left({ }^{\circ} \mathrm{C}\right)$ e respectivos desvios padrão para cada tipo de fonte de luz utilizada.

\begin{tabular}{cc}
\hline \hline Fonte de Luz & $\Delta \mathbf{T}\left({ }^{\circ} \mathbf{C}\right)$ \\
\hline \hline LED & $10,76 \pm 2,48^{\mathrm{a}}$ \\
HALÓGENA & $7,43 \pm 2,23^{\mathrm{b}}$ \\
\hline \hline
\end{tabular}

Letras diferentes indicam diferença estatística $(\mathrm{p}<0,05)$

Para o fator remanescente dental observou-se que o subgrupo com espessura de 3,5 mm apresentou menor variação de temperatura e diferiu estatisticamente $(p<0,05)$ dos demais. O subgrupo com espessura de $1,0 \mathrm{~mm}$ apresentou a maior variação de temperatura e foi estatisticamente diferente $(\mathrm{p}<0,05)$ dos subgrupos de 2,0 $\mathrm{mm}$ e 3,0 $\mathrm{mm}$ que apresentaram comportamento semelhante entre si (Tabela 5). 
A interação entre os fatores fonte de luz e remanescente dental é apresentada na Tabela 6. Para cada um dos remanescentes dentais, o LED produziu temperaturas mais elevadas e significativas $(\mathrm{p}<0,05)$ do que a luz halógena. A comparação entre as diferentes espessuras de remanescentes na mesma unidade de fotoativação evidenciou semelhança ( $>>0,05$ ) entre $2 \mathrm{~mm}$ e $1 \mathrm{~mm}$, e $3 \mathrm{~mm}$ e $2 \mathrm{~mm}$ para unidade LED, enquanto que para a luz halógena, não houve diferença $(\mathrm{p}>0,05)$ apenas entre $3 \mathrm{~mm}$ e $2 \mathrm{~mm}$. Aumentos de temperatura semelhante $(p>0,05)$ foram encontrados entre as duas unidades de fotoativação para LED/3.5 mm e halógena/3 $\mathrm{mm}$ e $2 \mathrm{~mm}$.

Tabela 5 - Variação de temperatura média $\left({ }^{\circ} \mathrm{C}\right)$ e respectivos desvios padrão para cada espessura $(\mathrm{mm})$ de remanescente dental.

\begin{tabular}{cc}
\hline \hline Remanescente & Temperatura $\left({ }^{\circ} \mathbf{C}\right)$ \\
\hline \hline $\mathbf{3 , 5} \mathbf{~ m m}$ & $6,44 \pm 1,56^{\mathrm{a}}$ \\
$\mathbf{3 , 0} \mathbf{~ m m}$ & $9,17 \pm 2,48^{\mathrm{b}}$ \\
$\mathbf{2 , 0} \mathbf{~ m m}$ & $9,77 \pm 2,62^{\mathrm{b}}$ \\
$\mathbf{1 , 0} \mathbf{~ m m}$ & $11,00 \pm 2,68^{\mathrm{c}}$ \\
\hline \hline
\end{tabular}

Letras diferentes indicam diferença estatística $(\mathrm{p}<0,05)$

Tabela 6 - Variação de temperatura média $\left({ }^{\circ} \mathrm{C}\right)$ e respectivos desvios padrão dos tipo de fonte de luz utilizada em cada espessura de remanescente dental.

\begin{tabular}{ccccc}
\hline \hline Remanescente & $\mathbf{3 , 5} \mathbf{~ m m}$ & $\mathbf{3 , 0} \mathbf{~ m m}$ & $\mathbf{2 , 0} \mathbf{~ m m}$ & $\mathbf{1 , 0} \mathbf{~ m m}$ \\
\hline \hline LED & $7,38 \pm 0,92^{\mathrm{b}}$ & $10,91 \pm 2,00^{\mathrm{d}}$ & $11,88 \pm 1,24^{\mathrm{d}, \mathrm{e}}$ & $12,87 \pm 1,09^{\mathrm{e}}$ \\
HALÓGENA & $5,49 \pm 1,53^{\mathrm{a}}$ & $7,41 \pm 1,48^{\mathrm{b}}$ & $7,66 \pm 1,76^{\mathrm{b}}$ & $9,14 \pm 2,49^{\mathrm{c}}$ \\
\hline \hline
\end{tabular}

Letras iguais indicam similaridade estatística $(p>0,05)$ 


\subsection{Variação de temperatura atingida em cada camada do procedimento restaurador}

$\mathrm{Na}$ análise do fator fonte de luz demonstrou que não houve diferença significante $(\mathrm{p}>0,05)$ durante a fotopolimerização do sistema adesivo, entretanto, os valores da variação de temperatura ocorrida durante a fotopolimerização de cada camada da resina composta utilizando a fonte de luz LED foram estatisticamente superiores a luz halógena (Tabela 7).

Tabela 7 - Variação de temperatura média $\left({ }^{\circ} \mathrm{C}\right)$ e respectivos desvios padrão para cada tipo de fonte de luz utilizada em cada camada.

\begin{tabular}{ccccc}
\hline \hline Fonte de Luz & Adesivo & $\begin{array}{c}\text { Primeira } \\
\text { camada }\end{array}$ & $\begin{array}{c}\text { Segunda } \\
\text { camada }\end{array}$ & $\begin{array}{c}\text { Terceira } \\
\text { camada }\end{array}$ \\
\hline \hline LED & $5,91 \pm 1,21^{\mathrm{a}}$ & $8,71 \pm 1,57^{\mathrm{a}}$ & $10,98 \pm 1,53^{\mathrm{a}}$ & $12,07 \pm 1,62^{\mathrm{a}}$ \\
HALÓGENA & $5,74 \pm 1,99^{\mathrm{a}}$ & $6,97 \pm 1,97^{\mathrm{b}}$ & $8,16 \pm 2,04^{\mathrm{b}}$ & $8,24 \pm 2,09^{\mathrm{b}}$ \\
& & & & \\
\hline \hline
\end{tabular}

Letras diferentes indicam diferença estatística $(\mathrm{p}<0,05)$ na comparação da coluna

Para $o$ fator remanescente dental pode-se observar que em cada camada fotopolimerizada (adesivo e incrementos de resina composta) houve diferença estatística significante $(\mathrm{p}<0,05)$ entre os níveis de remanescente dental (Tabela 8$)$.

$\mathrm{Na}$ fotopolimerização do adesivo o subgrupo com remanescente de 3,5 $\mathrm{mm}$ apresentou-se semelhante $(p>0,05)$ ao remanescente de $3,0 \mathrm{~mm}$ e diferente $(p<0,05)$ dos demais níveis de variação do fator remanescente. O subgrupo com remanescente de 3,0 mm foi semelhante $(\mathrm{p}>0,05)$ ao de $2,0 \mathrm{~mm}$, porém diferente $(\mathrm{p}<0,05)$ do subgrupo de $1,0 \mathrm{~mm}$ que apresentou o maior valor de variação de temperatura atingindo $7,34 \pm 1,64^{\circ} \mathrm{C}$ (Tabela 8 ).

A variação de temperatura durante a fotopolimerização do primeiro incremento de resina composta apresentou que os subgrupos de $3,5 \mathrm{~mm}$ de espessura e o de $1 \mathrm{~mm}$ diferiram 
entre si $(p<0,05)$ e dos demais subgrupos. Entretanto, os subgrupos com espessuras de 2,0 e 3,0 mm apresentaram comportamento semelhante $(p>0,05)$.

$\mathrm{Na}$ fotopolimerização do segundo e do terceiro incrementos de resina composta os subgrupos se comportaram da mesma maneira. Entre os níveis de 2,0 e 3,0 mm de espessura de remanescente não houve diferença significativa $(p>0,05)$, entretanto os mesmos foram diferentes $(\mathrm{p}<0,05)$ do grupo com remanescente de $1,0 \mathrm{~mm}$.

Tabela 8 - Variação de temperatura média $\left({ }^{\circ} \mathrm{C}\right)$ e respectivos desvios padrão registrada nos remanescentes dentais em cada camada fotopolimerizada.

\begin{tabular}{ccccc}
\hline \hline Remanescente & Adesivo & $\begin{array}{c}\text { Primeiro } \\
\text { incremento }\end{array}$ & $\begin{array}{c}\text { Segundo } \\
\text { incremento }\end{array}$ & $\begin{array}{c}\text { Terceiro } \\
\text { incremento }\end{array}$ \\
\hline \hline $\mathbf{3 , 5} \mathbf{~ m m}$ & $4,72 \pm 1,18^{\mathrm{a}}$ & $6,53 \pm 1,49^{\mathrm{a}}$ & -- & -- \\
$\mathbf{3 , 0} \mathbf{~ m m}$ & $5,29 \pm 1,40^{\mathrm{ab}}$ & $7,46 \pm 1,81^{\mathrm{b}}$ & $8,62 \pm 2,07^{\mathrm{a}}$ & $9,24 \pm 2,49^{\mathrm{a}}$ \\
$\mathbf{2 , 0} \mathbf{~ m m}$ & $5,95 \pm 1,04^{\mathrm{b}}$ & $7,94 \pm 1,59^{\mathrm{b}}$ & $9,38 \pm 2,15^{\mathrm{a}}$ & $9,90 \pm 2,62^{\mathrm{a}}$ \\
& & & & \\
$\mathbf{1 , 0} \mathbf{~ m m}$ & $7,34 \pm 1,64^{\mathrm{c}}$ & $9,44 \pm 1,86^{\mathrm{c}}$ & $10,72 \pm 2,22^{\mathrm{b}}$ & $11,32 \pm 2,58^{\mathrm{b}}$ \\
\hline \hline
\end{tabular}

Letras diferentes indicam diferença estatística $(\mathrm{p}<0,05)$ na comparação das linhas

Nas figuras 4 a 7 foram realizadas as comparações entre os grupos para a mesma espessura de remanescente, e observa-se que o comportamento do grupo do LED apresentou de maneira geral uma maior variação de temperatura durante todo o processo restaurador. 


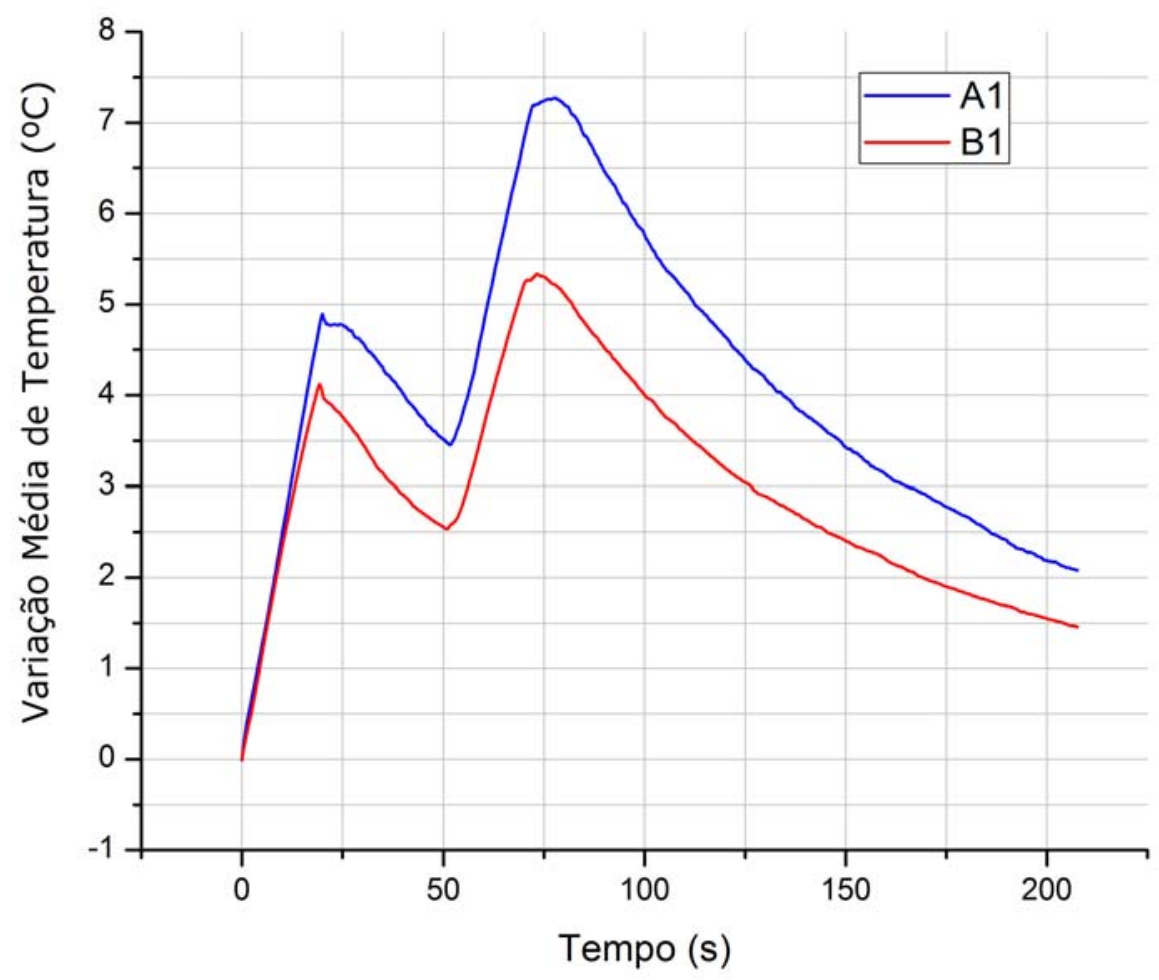

Figura 4. Variação de temperatura média $\left({ }^{\circ} \mathrm{C}\right)$ registrada em cada camada fotopolimerizada nos grupos/subgrupos A1 e B1.

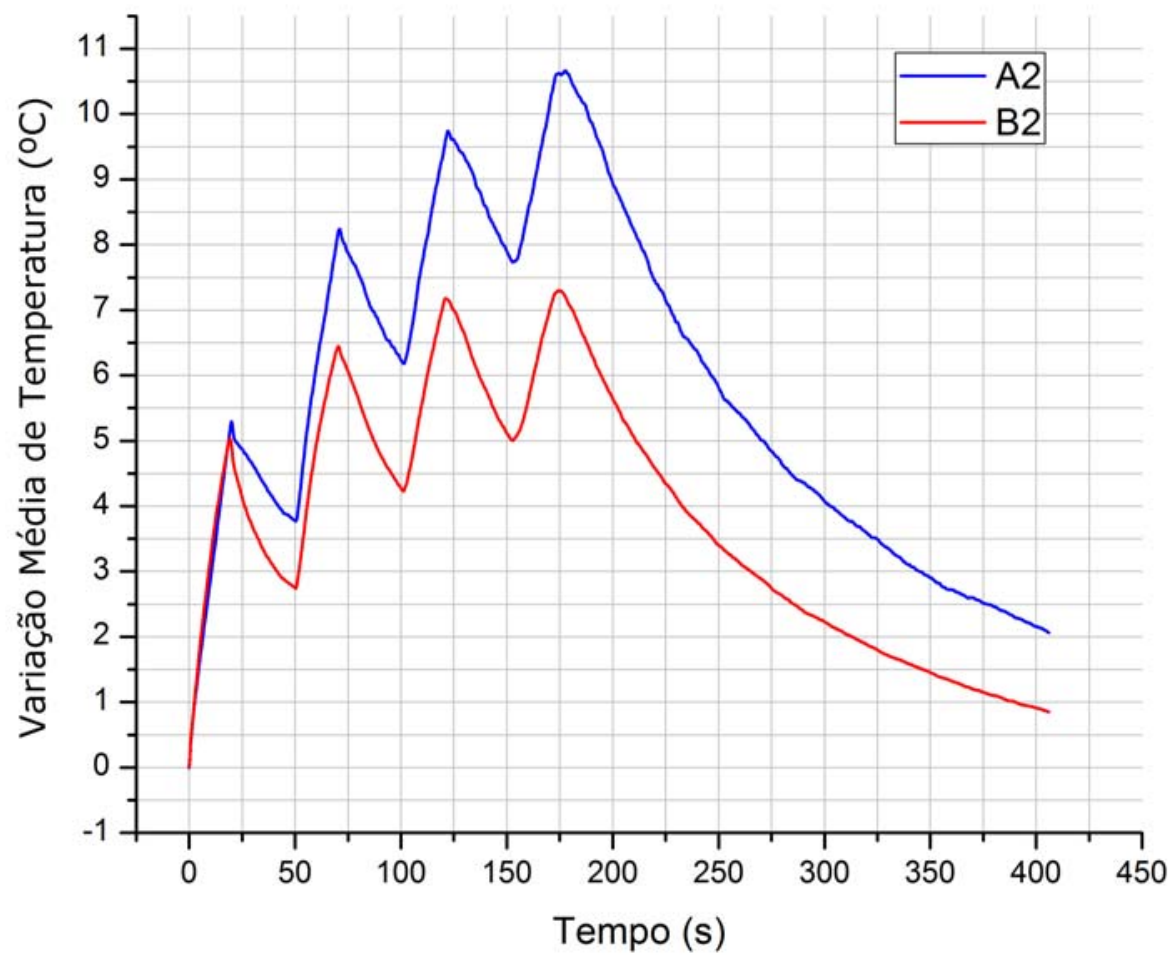

Figura 5. Variação de temperatura $\left({ }^{\circ} \mathrm{C}\right)$ registrada em cada camada fotopolimerizada nos grupos/subgrupos A2 e B2. 


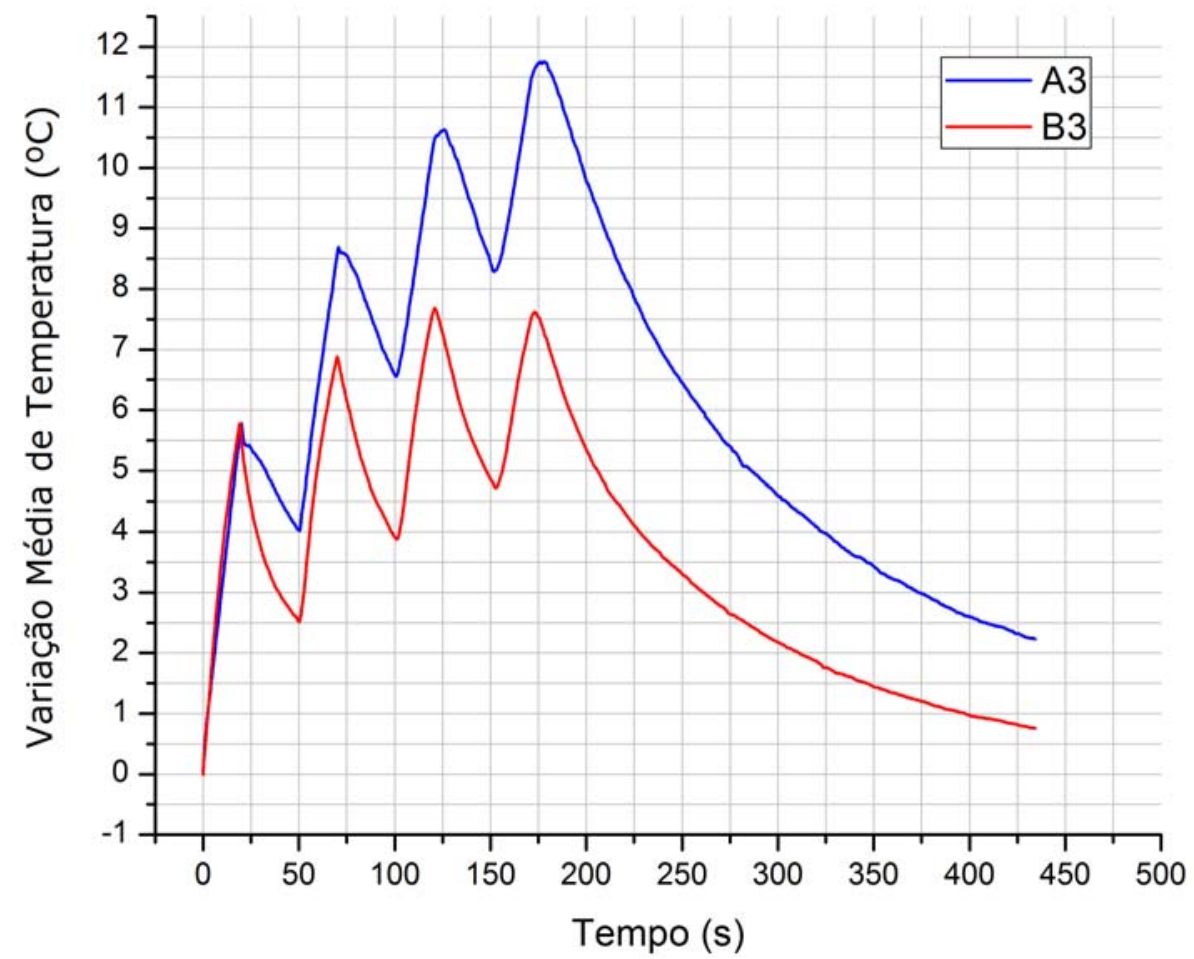

Figura 6. Variação de temperatura $\left({ }^{\circ} \mathrm{C}\right)$ registrada em cada camada fotopolimerizada nos grupos/subgrupos A3 e B3.

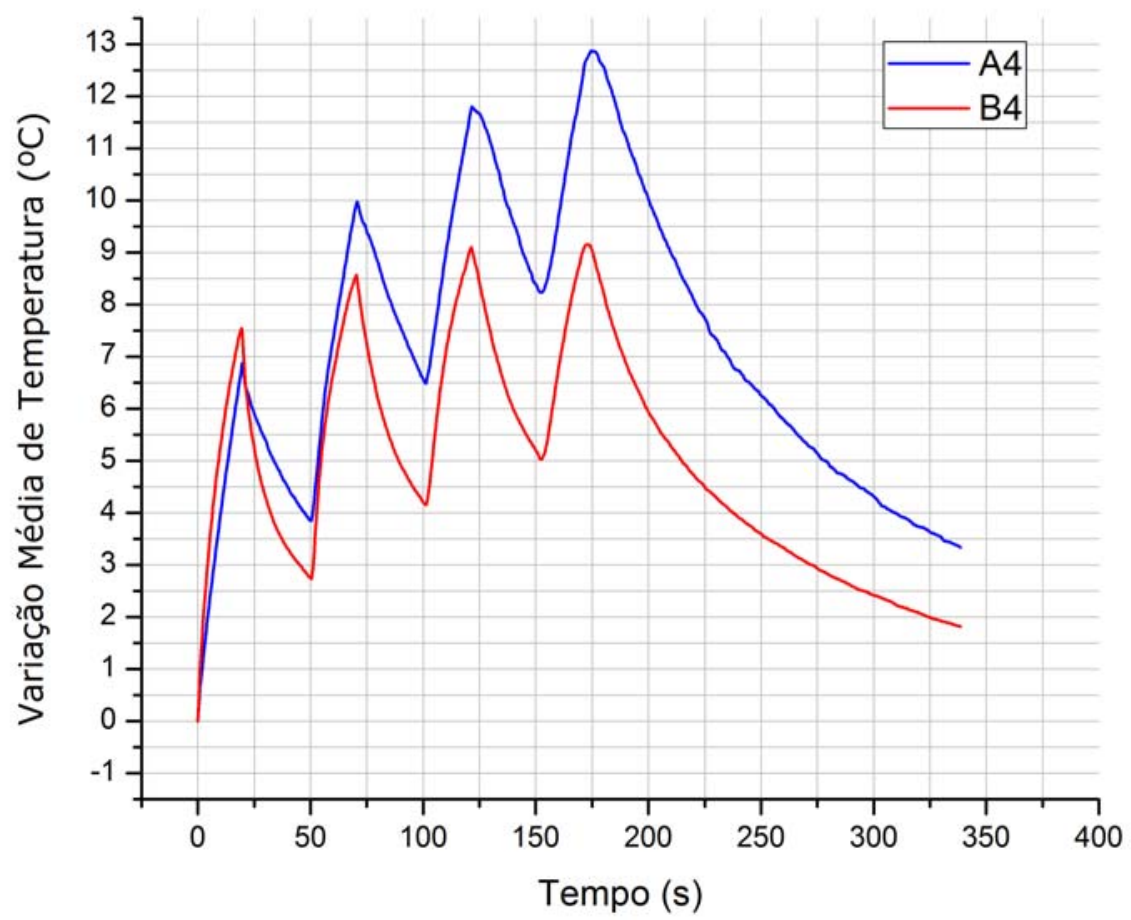

Figura 7. Variação de temperatura $\left({ }^{\circ} \mathrm{C}\right)$ registrada em cada camada fotopolimerizada nos grupos/subgrupos A4 e B4. 
Os valores médios e os desvios padrão do aumento de temperatura obtido durante a fotopolimerização do adesivo e dos incrementos de resina composta em cada espessura de remanescente dental utilizando as fontes de luz LED e Halógena estão descritos na Tabela 9.

Os dados demonstraram (Figura 8 e Tabela 9) que para ambas as fontes de luz LED e halógena, o aumento de temperatura medido com 3,5 $\mathrm{mm}$ de espessura de remanescente dental durante a fotopolimerização do agente adesivo foi significantemente $(p<0,05)$ menor do que o primeiro incremento de resina composta; para o remanescente com espessura de 2 mm, o valor de temperatura durante a fotopolimerização do agente adesivo foi diferente $(p<0,05)$ de todos os incrementos, e não houve diferença $(p>0,05)$ entre o primeiro e o segundo incremento. Nos remanescentes com $1 \mathrm{~mm}$ e $3 \mathrm{~mm}$ de espessura de remanescente houveram aumentos de temperatura semelhantes $(p>0,05)$ durante a fotopolimerização do agente adesivo e o primeiro incremento somente para a fonte de luz LED, enquanto que os valores de temperatura foram similares $(p>0,05)$ entre as duas fontes de luz durante a fotoativação do primeiro e o segundo incremento e durante o segundo e o terceiro incremento fotoativado.

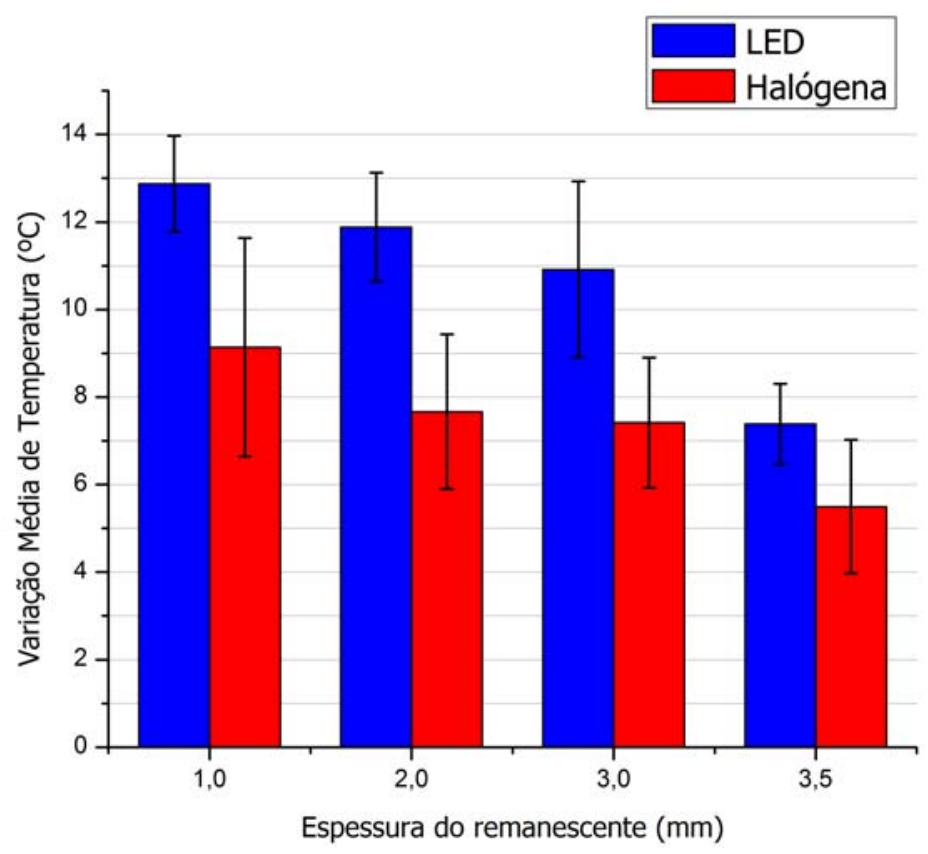

Figura 8. Variação média de temperatura registrada nas diferentes espessuras de remanescentes dentais para cada fonte de luz. 
Tabela 9 - Variação média de temperatura e respectivo desvio padrão $\left({ }^{\circ} \mathrm{C}\right)$ registrada para os grupos/subgrupos estudados.

\begin{tabular}{|c|c|c|c|c|}
\hline \multicolumn{5}{|c|}{$\overline{\text { LED }}$} \\
\hline Remanescente & Adesivo & $\begin{array}{c}\text { Primeiro } \\
\text { incremento }\end{array}$ & $\begin{array}{c}\text { Segundo } \\
\text { incremento }\end{array}$ & $\begin{array}{c}\text { Terceiro } \\
\text { incremento }\end{array}$ \\
\hline $3,5 \mathrm{~mm}$ & $5,14 \pm 0,67^{\mathrm{a}}$ & $7,44 \pm 0,87^{\mathrm{b}}$ & -- & -- \\
\hline $3,0 \mathrm{~mm}$ & $5,41 \pm 1,27^{\mathrm{a}}$ & $8,34 \pm 1,70^{\mathrm{a}, \mathrm{b}}$ & $9,92 \pm 1,68^{\mathrm{b}, \mathrm{c}}$ & $11,02 \pm 1,81^{\mathrm{c}}$ \\
\hline $2,0 \mathrm{~mm}$ & $6,06 \pm 0,75^{\mathrm{a}}$ & $8,90 \pm 1,04^{\mathrm{b}}$ & $10,95 \pm 1,13^{\mathrm{b}}$ & $12,04 \pm 1,17^{\mathrm{c}}$ \\
\hline $1,0 \mathrm{~mm}$ & $7,05 \pm 1,13^{\mathrm{a}}$ & $10,16 \pm 1,25^{\mathrm{a}, \mathrm{b}}$ & $12,09 \pm 0,91^{\mathrm{b}, \mathrm{c}}$ & $13,15 \pm 1,13^{c}$ \\
\hline \multicolumn{5}{|c|}{ Halógena } \\
\hline Remanescente & Adesivo & $\begin{array}{c}\text { Primeiro } \\
\text { incremento }\end{array}$ & $\begin{array}{c}\text { Segundo } \\
\text { incremento }\end{array}$ & $\begin{array}{c}\text { Terceiro } \\
\text { incremento }\end{array}$ \\
\hline $3,5 \mathrm{~mm}$ & $4,31 \pm 1,44^{\mathrm{a}}$ & $5,62 \pm 1,45^{b}$ & -- & -- \\
\hline $3,0 \mathrm{~mm}$ & $5,17 \pm 1,57^{\mathrm{a}}$ & $6,56 \pm 1,50^{b}$ & $7,33 \pm 1,58^{\mathrm{b}, \mathrm{c}}$ & $7,47 \pm 1,67^{\mathrm{c}}$ \\
\hline $2,0 \mathrm{~mm}$ & $5,85 \pm 1,30^{\mathrm{a}}$ & $6,96 \pm 1,48^{b}$ & $7,81 \pm 1,75^{\mathrm{b}}$ & $7,76 \pm 1,74^{\mathrm{c}}$ \\
\hline $1,0 \mathrm{~mm}$ & $7,65 \pm 2,04^{\mathrm{a}}$ & $8,72 \pm 2,13^{b}$ & $9,35 \pm 2,31^{\mathrm{b}, \mathrm{c}}$ & $9,50 \pm 2,34^{\mathrm{c}}$ \\
\hline
\end{tabular}

Letras iguais indicam similaridade estatística $(p>0,05)$ na comparação entre linhas. 


\section{Discussão}




\section{Discussão}

Os procedimentos realizados na superfície do dente normalmente geram estímulos térmicos que podem ser nocivos aos tecidos dentais (EBERHARD et al., 2005). Desde a confecção do preparo cavitário, reação exotérmica dos materiais forradores e restauradores, bem como a fotopolimerização de compósitos resinosos (McCABE; WILSON, 1980; UHL; MILLS; JANDT, 2003; KNEZEVIC et al., 2005; TAHER et al., 2008) promovem o aumento da temperatura intrapulpar, e este fato vem sendo motivo de preocupação na Odontologia (ZACH; COHEN, 1965; HANNING; BOTT, 1999; BOUILLAGUET et al.,2005; JAKUBINEK et al., 2008; LEE et al., 2008).

Dentre os fatores mais preocupantes tem-se a fotoativação dos compósitos, durante o procedimento restaurador, pois demonstra ser um dos principais responsáveis pela geração de calor (HANSEN; ASMUSSEN, 1993; BAGIS et al., 2008), que varia de acordo com intensidade, magnitude e do tempo de duração do estímulo (McCABE, 1985; MASUTANI et al., 1988; HANNING; BOTT, 1999; KNEZEVIC et al., 2005; UHL, VÖLPEL, SIGUSH, 2006).

No presente estudo observou-se que o procedimento restaurador promoveu uma elevação acentuada da temperatura no teto da câmara pulpar, este fato ocorreu devido à absorção da energia produzida pela fonte de luz (HANSEN; ASMUSSEN, 1993; HANNING; BOTT, 1999; PRICE et al., 2003; DANESH et al., 2004; KNEZEVIC et al., 2005) e pela reação exotérmica de polimerização do compósito durante o processo de fotoativação, embora a contribuição do calor desenvolvido pela reação química seja um fator secundário quando 
comparado a demanda de energia proporcionada pelo equipamento de fotoativação (LLOYD et al., 1986; MASUTANI et al., 1988; SHORTALL; HARRINGTON, 1998; BAGIS et al., 2008; GUIRALDO et al., 2008). Os resultados demonstram que o aumento de temperatura poderia ser suficiente para causar lesão ao tecido pulpar, em função que, ocorreram aumentos superiores a $5,5^{\circ} \mathrm{C}(\mathrm{ZACH}$; $\mathrm{COHEN}, 1965)$, que poderiam inclusive levar a necrose pulpar dependendo do estado do sistema circulatório da polpa (BAGIS et al., 2008).

Outro fator que pode ser observado é que o aumento de temperatura foi influenciado pelo equipamento de fotoativação tendo o LED (Tabela 4) apresentado maiores valores de temperatura em comparação ao Halógena durante o procedimento restaurador, confirmando os resultados obtidos nos estudos de Bagis et al. (2008), Durey, Santini, Miletic. (2008) e Guiraldo et al. (2008). Isso pode ser decorrente ao fato de que o aparelho LED emite comprimento de onda mais específico e mais próximo do espectro de absorção da canforoquinona do que a luz halógena convencional (BURGESS et al., 2002; LEONARD et al., 2002), na qual cerca de $80 \%$ da energia acaba sendo dissipada e apenas pequena fração efetivamente participa da polimerização do compósito. No caso do LED praticamente 100\% da energia emitida é convertida na ativação do fotoiniciador canforoquinona. (KURACHI et al., 2001).

Assim, quanto maior o grau de conversão do compósito maior será a reação exotérmica do processo de polimerização da resina e conseqüentemente maior a temperatura atingida (HALVORSON; ERICKSON; DAVIDSON, 2002, KNEZEVIC et al., 2001), porém o grau de conversão dos compósitos está diretamente relacionado à densidade de energia (intensidade X tempo de exposição) do equipamento (RUEGGEBERG, 1999; YAP; SENEVIRATNE, 2001). Contudo, durante a fotoativação ocorrem desigualdades nos níveis de penetração de luz nos compósitos, dependentes da absorção e reflexão da luz pelas partículas de carga (MASUTANI et al., 1988, FUJITA et al., 2005) demonstrado que o índice 
de refração e o tamanho das partículas de carga interferem sobremaneira na dispersão da luz e, conseqüentemente, na profundidade de polimerização e grau de conversão (FUJITA et al., 2005). Um pequeno aumento na profundidade de polimerização é seguido por um aquecimento desproporcional do tecido pulpar (KNEZEVIC et al., 2001; KNEZEVIC et al., 2005). Para evitar a influência do material e avaliar realmente o efeito do equipamento, neste estudo foi utilizado apenas um único tipo de resina composta.

Pode ser observado no presente estudo que a transmissão térmica do calor desenvolvido durante a fotopolimerização do compósito pode também ser afetada pela espessura do remanescente dental (Tabela 5), sendo que o aumento de temperatura foi inversamente proporcional a quantidade de substrato, ocorrendo um aumento gradativo de temperatura à medida que diminuiu a espessura da dentina, ou seja, quanto maior a espessura do remanescente dental menor a elevação da temperatura, devido à baixa condutibilidade térmica do substrato dental (LONEY; PRICE, 2001). Estudos (TJAN; DUNN, 1988; PRICE; MURPHY; DÉRAND, 2000; LONEY; PRICE, 2001; YAZICI et al., 2006; YAZICI; MÜFTÜ; KUGEL, 2007) observaram resultados similares em que a espessura do remanescente dentinário afetou o aumento de calor gerado.

Assim, pode-se observar neste trabalho que os subgrupos com remanescente dental de $3,5 \mathrm{~mm}$ apresentaram o menor aumento de temperatura $\left(6,44^{\circ} \mathrm{C} \pm 1,56\right)$, que pode ser justificado pela presença de $3,0 \mathrm{~mm}$ de tecido dentinário acrescido de $0,5 \mathrm{~mm}$ de esmalte, este por sua vez, pode ter funcionado como isolante térmico, somado a isso, estes subgrupos receberam menos fotoativações, apenas 2 vezes, uma referente a aplicação do agente adesivo e outra referente ao compósito, promovendo um menor acúmulo de calor. Dessa maneira, o maior aumento de temperatura registrado durante todo o procedimento restaurador foi para os subgrupos com 1,0 $\mathrm{mm}$ de espessura de remanescente dentinário $\left(11,00^{\circ} \mathrm{C} \pm 2,68\right)$, corroborando os resultados encontrados no estudo de Yazici, Müftü, Kugel (2007) o que 
sugere uma relação inversa entre a espessura dentinária e aumento de temperatura, em função dos coeficientes de condutividade térmica (LONEY; PRICE, 2001) dos substratos e do material resinoso. A condutividade térmica $(\mathrm{K})$ de uma substância é a quantidade de calor, em calorias ou joules por segundo que passam ao longo de 1 centímetro de espessura do material, com uma secção transversal com $1 \mathrm{~cm}^{2}$, quando a diferença de temperatura for $1^{\circ} \mathrm{C}$. A resina composta tem um coeficiente de condutividade térmica cerca de $0,011 \mathrm{~J} / \mathrm{s} / \mathrm{cm}^{2} /\left({ }^{\circ} \mathrm{C} / \mathrm{cm}\right)$ e a dentina de $0,0063 \mathrm{~J} / \mathrm{s} / \mathrm{cm}^{2} /\left({ }^{\circ} \mathrm{C} / \mathrm{cm}\right)$, o que resulta em quase duas vezes mais a passagem do calor para o substratos adjacentes (CRAIG; POWERS, 2004). Em outras palavras, a dentina funciona como isolador térmico (UHL et al., 2006), mas depende da sua espessura, da quantidade de calor depositado ou do tempo de resfriamento e da diferença de temperatura (CRAIG; POWERS, 2004) que atinge o substrato.

Analisando separadamente a temperatura alcançada nas camadas fotoativadas (Tabela 7) verificou-se que durante a fotoativação do agente adesivo houve a maior variação de temperatura confirmando os resultados achados por Millen et al., 2007. Mas, não foi a maior temperatura atingida no procedimento restaurador, devido à polimerização do agente adesivo ter sido a primeira a ser realizada. Desta forma pois o espécime saiu de uma temperatura inicial (ambiente) sem apresentar o calor residual acumulado de uma fotoativação anterior, ocorrendo um aumento gradativo nos valores de temperatura atingidos nas demais camadas fotopolimerizadas. Assim, a cada fotoativação realizada (incrementos de compósito) a temperatura registrada foi ainda maior, pois além de receber uma nova incidência de luz e resultar em mais uma reação de polimerização do material houve ainda o calor residual da fotoativação anterior (Figuras 4 - 7), potencializando a elevação de temperatura no teto da câmara pulpar.

Estudos anteriores (LLOYD et al. 1986; SHORTALL; HARRINGTON, 1998) observaram que a temperatura aumentava com a diminuição da espessura do compósito, 
ocorrendo a elevação da temperatura quando a luz foi aplicada sobre a cavidade vazia, ou seja, o aumento de temperatura foi menor com a presença do compósito. Nessas condições, o calor disponível possivelmente seria menor e teria maior dificuldade para atingir a câmara pulpar devido à capacidade atenuante do material exceder ao calor gerado pelo equipamento de polimerização, na base da parede pulpar. Pode-se supor que a maior injúria pulpar ocorreria na polimerização do adesivo, quando comparado com a resina composta. Entretanto esta hipótese não é adequada, pois com o aumento da espessura do compósito há também um aumento na quantidade de reações químicas transformando monômeros em polímeros e conseqüentemente maior liberação de calor, além do acúmulo de calor gerado durante as sucessivas fotoativações.

Assim, poderia-se afirmar que uma quantidade reduzida de compósito e/ou uma unidade de baixa intensidade de luz produziriam menor estresse térmico sobre os tecidos pulpares (UHL; MILLS; JANDT, 2003) e que seria mais adequada à técnica incremental para se ter menor aumento de temperatura (MASUTAMI et al. 1988). Contudo, observou-se no presente estudo, que quanto mais fotoativações foram realizadas, maiores os valores de temperatura no teto da câmara pulpar, potencializando possíveis efeitos indesejáveis ao tecido, devido ocorrer o calor residual durante o processo restaurador. Os substratos e a resina composta não conseguiram retornar a temperatura inicial, o que necessitaria de mais tempo de espera entre uma fotopolimerização e outra, o que poderia proporcionar um menor trauma térmico e menor reação pulpar, pois o tecido teria mais tempo para se adaptar e compensar a agressão (UHL; MILLS; JANDT, 2003).

$\mathrm{Na}$ literatura pode-se observar que na maioria dos estudos (SHORTALL; HARRINGTON, 1998; BOUILLAGUET et al., 2005; AGUIAR et al., 2005; AWLIYA, 2007; YAZICI et al., 2006; YAZICI; MÜFTÜ; KUGEL, 2007) em que analisam a variação de temperatura durante a fotopolimerização da resina é realizada apenas uma fotoativação 
variando-se a espessura do remanescente e o material restaurador, não analisando o calor acumulado ao longo do processo restaurador, dificultando a comparação dos resultados. Desta maneira, Guiraldo et al. (2008) verificaram que a espessura de remanescente dentinário não influenciou no aumento de temperatura durante a fotoativação de compósitos, ou mesmo, em cavidades com remanescente de $1 \mathrm{~mm}$ de dentina (HANNING; BOTT, 1999), não promoveram aumentos semelhantes aos encontrados na presente pesquisa.

De maneira geral, a maioria dos clínicos não tem conhecimento do aumento de temperatura que ocorre durante o procedimento restaurador com compósitos ou da relação quanto maior a espessura do remanescente dental e menor a quantidade de fotoativações menor o aumento da temperatura. Por outro lado, a utilização de altas intensidades tem sido sugerida para reduzir o tempo de polimerização (JAKUBINEK et al., 2008). Entretanto, maior velocidade de polimerização pode produzir menor grau de conversão em todas as profundidades do material (TARLE et al., 2002), prejudicar as propriedades dos materiais restauradores (YAP; SENEVIRATNE, 2001), além de promover maiores aumentos de temperatura intra-pulpar (ASMUSSEN; PEUTZFELDT, 2005; YAZICI et al., 2006; MILLEN et al., 2007).

Sugere-se a utilização de protetores pulpar para permitir o isolamento térmico adequado ou manter procedimentos para prover suficiente espessura de dentina (HUSSEY et al., 1995; DARONCH et al., 2007). Com base nesses critérios, se um aumento de temperatura da ordem de $12^{\circ} \mathrm{C}$ ocorrer nos procedimentos de fotoativação, ele seria por um curto período de tempo. Porém, clinicamente é impossível predizer o aumento de temperatura que possa ocorrer durante a restauração com compósitos. Em geral, quanto maior a espessura da dentina remanescente, menor será o aumento da temperatura (LONEY; PRICE, 2001; AGUIAR et al., 2005; YAZICI et al., 2006). O efeito dessa transmissão térmica sobre a polpa é mais 
importante que a condutividade térmica da dentina ou do tipo de material restaurador aplicado ao dente (TAKAHASHI; KITAGAMI; KOMORI, 1977).

O menor aquecimento gerado em restaurações de compósito é importante não só para integridade do tecido pulpar, mas também influencia na susceptibilidade à sensibilidade pósoperatória (KNEZEVIC et al., 2005). Assim, desenvolver protocolos de restaurações que considerarem as implicações de temperatura é a forma mais promissora de reduzir o risco de lesão térmica pulpar, uma vez que, uma grande porção do aumento de temperatura é resultante da fonte de luz polimerizadora.

A maioria dos estudos avalia as modificações dentro do tecido pulpar causado por estimulação térmica utilizando técnicas histológicas (ZACH; COHEN 1965, OZTURK et al., 2004). Estes estudos só podem demonstrar mudanças visíveis das células, mas não foram concebidos para revelar inicialmente as reações inflamatórias ou alterações metabólicas no interior das mesmas (EBERHARD et al, 2005).

Para a avaliação das mudanças celulares que poderiam ser induzidas pelo choque térmico uma ferramenta valiosa poderia ser a avaliação dos mediadores inflamatórios sintetizados por células de origem pulpar (AMANO et al., 2006; LEE et al., 2008). Os aumentos dos níveis de tais mediadores em tecidos humanos humorais podem causar reações inflamatórias levando à necrose celular (EBERHARD et al., 2005).

Por essa razão, se a espessura da dentina for mínima, não é prudente colocar fontes de luz com alta intensidade em contato direto com o substrato dentinário (LONEY; PRICE, 2001), deve-se preconizar o uso de materiais de forramento nestas cavidades (SHORTALL; HARRINGTON, 1998), eleger aparelhos com intensidade média de energia, e aguardar um período de tempo maior que 30 segundos entre as camadas de ativação para que ocorra a dissipação do calor através das paredes laterais da cavidade para o interior da dentina e através da parede virtual para o meio ambiente. 
Conforme visto neste estudo, a variação térmica ocorrida na polimerização do compósito depende da intensidade de energia da fonte fotopolimerizadora e da espessura do remanescente dental. Contudo, outros fatores devem ser considerados, tais como o comprimento de onda do equipamento e o tipo de matriz da resina composta. Tendo em vista a complexidade da avaliação da temperatura, outros estudos seriam necessários para complementar as informações obtidas neste trabalho, uma vez que a extensão da lesão térmica que pode ser tolerada pela polpa dentária é desconhecida (BALDISSARA et al., 1997, STEWARDSON et al., 2004; MILLEN et al., 2007). 


\section{Conclusões}




\section{Conclusões}

De acordo com os resultados obtidos, foi possível concluir que:

- As fontes de luz influenciaram o aumento de temperatura durante o procedimento restaurador, sendo que o LED produziu temperaturas mais elevadas do que a luz halógena;

- A quantidade de fotoativações interferiu diretamente no aumento de temperatura durante o procedimento restaurador. A cada fototivação ocorreu uma sensível elevação de temperatura;

- A espessura do remanescente dental mostrou influenciar no aumento da temperatura durante a fotoativação. Quanto menor a espessura de remanescente dental, maior a temperatura atingida;

- Independente dos fatores analisados, o processo restaurador promoveu uma variação de temperatura superior a $5,5^{\circ} \mathrm{C}$. 
Referências Bibliográficas 


\section{REFERÊNCIAS BibLIOGRÁFICAS ${ }^{*}$}

AGUIAR, F.H.; BARROS, G.K.; DOS SANTOS, A.J.; AMBROSANO, G.M.; LOVADINO, J.R. Effect of polymerization modes and resin composite on the temperature rise of human dentin of different thicknesses: an in vitro study. Oper Dent, v.30, p.602-607, 2005.

AL-QUDAH, A.A.; MITCHELL, C.A.; BIAGIONI, P.A.; HUSSEY, D.L. Effect of composite shade, increment thickness and curing light on temperature rise during photocuring. J Dent, v.35, p.238-245, 2007.

Althoff, O.; HARTUng, M. Advances in light curing. Am J Dent, v.13, p.77D-81D, 2000 .

ALTINTAS, S.H.; YONDEM, I.; TAK, O.; USUMEZ, A. Temperature rise during polymerization of three different provisional materials. Clin Oral Investig, v.12, p.283-286, 2008.

AMANO, T.; MURAMATSU, T.; AMEMIYA, K.; KUBO, K.; SHIMONO, M. Responses of rat pulp cells to heat stress in vitro. J Dent Res, v.85, p.432-435, 2006.

ANUSAVICE, K.J. Phillips materiais dentários. 10.ed. Rio de Janeiro: Guanabara Koogan, 1998.

ASMUSSEN, E.; PEUTZFELDT, A. Temperature rise induced by some light emitting diode and quartz-tungsten-halogen curing units. Eur J Oral Sci, v.113, p.96-98, 2005.

AWLIYA, W.Y. The influence of temperature on the efficacy of polymerization of composite resin. J Contemp Dent Pract, v.8, p.9-16, 2007.

\footnotetext{
*De acordo com a NBR-6023, da Associação Basileira de Normas, de 2002.
}

Abreviaturas dos periódicos em conformidade com Baseline. 
BAGIS, B.; BAGIS, Y.; ERTAS, E.; USTAOMER, S. Comparison of the heat generation of light curing units. J Contemp Dent Pract, v.9, p.65-72, 2008.

BALDISSARA, P.; CATAPANO, S.; SCOTTI, R. Clinical and histological evaluation of thermal injury thresholds in human teeth: a preliminary study. J Oral Rehabil, v.24, p.791$801,1997$.

BOUILlaGUET, S.; CAILlOT, G.; FORCHELET, J.; CATTANI-LORENTE, M.; WATAHA, J.C.; KREJCI, I. Thermal risks from LED- and high-intensity QTH-curing units during polymerization of dental resins. J Biomed Mater Res B Appl Biomater, v.72, p.260267, 2005.

BOWEN, R.L. Properties of a silica-reinforced polymer for the dental restoration. J Am Dent Assoc, Chicago, v.66, p.57-64, 1963.

BROWN, W.S.; DEWEY, W.A.; JACOBS, M.R. Thermal properties of teeth. J Dent Res, v.49, p.752-755, 1970.

BURGESS, J.O.; WALKER, R.S.; PORCHE, C.J.; RAPPOLD, A.J. Light curing - an update. Compend Contin Educ Dent, v.23, p.889-892, 2002.

CAUGHMAN, W.F.; RUEGGEBERG, F.A. Shedding new light on composite polymerization. Oper Dent, v.27, p.636-638, 2002.

CRAIG, R.G.; POWERS, J.M. Materiais dentários restauradores. $11^{\circ}$ ed, São Paulo: Livraria Santos editora, p.50 -51, 2004.

DANESH, G.; DAVIDS, H.; DUDA, S.; KAUP, M.; OTT, K.; SCHÄFER, E. Temperature rise in the pulp chamber induced by a conventional halogen light-curing source and a plasma arc lamp. Am J Dent, v.17, p.203-208, 2004.

DARONCH, M.; RUEGGEBERG, F.A.; HALL, G.; DE GOES, M.F. Effect of composite temperature on in vitro intrapulpal temperature rise. Dent Mater, v.23, p.1283-1288. 2007.

DE LANGE, C.; BAUSCH, J.R.; DAVIDSON, C.L. The curing pattern of photo-initiated dental composites. J Oral Rehabil, v.7, p.369-377, 1980.

DUREY, K.; SANTINI, A.; MILETIC, V. Pulp chamber temperature rise during curing of resin-based composites with different light-curing units. Prim Dent Care, v.15, p.33-38, 2008. 
EBERHARD, J.; ZAHL, A.; DOMMISCH, H.; WINTER, J.; ACIL, Y.; JEPSEN, S. Heat shock induces the synthesis of the inflammatory mediator leukotriene B4 in human pulp cells. Int Endod J, v.38, p. 882-888, 2005.

FEILZER, A.J.; DOOREN, L.H.; DE GEE, A.J.; DAVIDSON, C.L. Influence of light intensity on polymerization shrinkage and integrity of restoration-cavity interface. Eur J Oral Sci, v.103, p.322-326, 1995.

FUJITA, K.; NISHIYAMA, N.; NEMOTO, K.; OKADA, T.; IKEMI, T. Effect of base monomer's refractive index on curing depth and polymerization conversion of photo-cured resin composites. Dent Mater J, v.24, p.403-408, 2005.

GUIRALDO, R.D.; CONSANI, S.; LYMPIUS, T.; SCHNEIDER, L.F.; SINHORETI, M.A.; CORRER-SOBRINHO, L. Influence of the light curing unit and thickness of residual dentin on generation of heat during composite photoactivation. J Oral Sci, v.50, p.137-142, 2008.

HALVORSON, R.H.; ERICKSON, R.L.; DAVIDSON, C.L. Energy dependent polymerization of resin-based composite. Dent Mater, v.18, p.463-469, 2002.

HANNIG, M.; BOTT, B. In-vitro pulp chamber temperature rise during composite resin polymerization with various light-curing sources. Dent Mater, v.15, p.275-281, 1999.

HANSEN, E.K.; ASMUSSEN, E. Correlation between depth of cure and temperature rise of a light-activated resin. Scand J Dent Res, v.101, p.176-179, 1993.

HOFMANN, N.; MARKERT, T.; HUGO, B.; KLAIBER, B. Effect of high intensity vs. softstart halogen irradiation on light-cured resin-based composites. Part I. Temperature rise and polymerization shrinkage. Am J Dent, v.16, p.421-430, 2003.

HUSSEY, D.L.; BIAGIONI, P.A.; LAMEY, P.J. Thermographic measurement of temperature change during resin composite polymerization in vivo. J Dent, v.23, p.267-271, 1995.

IRIE, M.; SUZUKI, K.; WATTS, D.C. Marginal gap formation of light-activated restorative materials: effects of immediate setting shrinkage and bond strength. Dent Mater, v.18, p.203$210,2002$.

JAKUBINEK, M.B.; O'NEILL, C.; FELIX, C.; PRICE, R.B.; WHITE, M.A. Temperature excursions at the pulp-dentin junction during the curing of light-activated dental restorations. Dent Mater, v.24, p.1468-1476, 2008. 
KITAMURA, C.; NISHIHARA, T.; UENO, Y.; NAGAYOSHI, M.; KASUGAI, S.; TERASHITA, M. Thermotolerance of pulp cells and phagocytosis of apoptotic pulp cells by surviving pulp cells following heat stress. J Cell Biochem, v.94, p.826-834, 2005.

KNEZEVIĆ, A.; TARle, Z.; MENIGA, A.; SUTAlO, J.; PICHLER, G.; RISTIĆ, M. Degree of conversion and temperature rise during polymerization of composite resin samples with blue diodes. J Oral Rehabil, v.28, p.586-591, 2001.

KNEZEVIĆ, A.; TARLE, Z.; MENIGA, A.; SUTALO, J.; PICHLER, G. Influence of light intensity from different curing units upon composite temperature rise. J Oral Rehabil, v.32, p.362-367, 2005.

KURACHI, C.; TUBOY, A.M.; MAGALHÃES, D.V.; BAGNATO, V.S. Hardness evaluation of a dental composite polymerized with experimental LED-based devices. Dent Mater, v.17, p.309-315, 2001.

LEE, H.L.; ORLOWSKI, J.A.; ROGERS, B.J. A comparison of ultraviolet-curing and selfcuring polymers in preventive, restorative and orthodontic dentistry. Int Dent J, v.26, p.134-151, 1976.

LEE, M.W.; MURAMATSU, T.; UEKUSA, T.; LEE, J.H.; SHIMONO, M. Heat stress induces alkaline phosphatase activity and heat shock protein 25 expression in cultured pulp cells. Int Endod J, v.41, p.158-162, 2008.

LEONARD, D.L.; CHARLTON, D.G.; ROBERT, H.W.; COHEN, M.E.; Polymerization efficiency of LED curing lights. J Esthet Rest, v.14, p.286-295, 2002.

LINSUWANONT, P.; PALAMARA, J.E.; MESSER, H.H. An investigation of thermal stimulation in intact teeth. Arch Oral Biol, v.52, p.218-227, 2007.

LISANTI, V.F.; ZANDER, H.A. Thermal injury to normal dog teeth: in vivo measurements to pulp temperature increases and their effect on the pulp tissue. J Dent Res, v.31, p.548-558, 1952.

LLOYD, CH.; JOSHI, A.; MCGLYNN, E. Temperature rises produced by light sources and composites during curing. Dent Mater, v.2, p.170-174, 1986.

LONEY, R.W.; PRICE, R.B. Temperature transmission of high-output light-curing units through dentin. Oper Dent, v.26, p.516-520, 2001. 
MARTINS, G.R.; CAVALCANTI, B.N.; RODE, S.M. Increases in intrapulpal temperature during polymerization of composite resin. J Prosthet Dent, v.96, p.328-331, 2006.

MASUTANI, S.; SETCOS, J.C.; SCHNELL, R.J.; PHILLIPS, R.W. Temperature rise during polymerization of visible light-activated composite resins. Dent Mater, v.4, p.174-178, 1988.

McCABE, J.F.; WILSON, H.J. The use of differential scanning calorimetry for the evaluation of dental materials. J Oral Rehabil, v.7, p.103-110, 1980.

McCABE J.F. Cure performance of light-activated-composites by differential thermal analysis (DTA). Dent Mater, v.1, p.231-234, 1985.

MEHL, A.; HICKEL, R.; KUNZELMANN, K.H. Physical properties and gap formation of light-cured composites with and without 'softstart-polymerization'. J Dent, v.25, p.321-330, 1997.

MILLEN, C.; ORMOND, M.; RICHARDSON, G.; SANTINI, A.; MILETIC, V.; KEW, P. A study of temperature rise in the pulp chamber during composite polymerization with different light-curing units. J Contemp Dent Pract, v.8, p.29-37, 2007.

MILLS, R.W. Blue light emitting diodes-an alternative method of curing? Brit Dent J, v.178, p.169, 1995.

MIYAZAKI, M.; OSHIDA, Y.; MOORE, B.K.; ONOSE, H. Effect of light exposure on fracture toughness and flexural strength of light-cured composites. Dent Mater, v.12, p.328332, 1996.

MONTGOMERY, D.C. Design and analysis of experiments. 5.ed. New York: John Wiley \& Sons, 2001.

OZTURK, B.; OZTURK, A.N.; USUMEZ, A.; USUMEZ, S.; OZER, F. Temperature rise during adhesive and resin composite polymerization with various light curing sources. Oper Dent, v.29, p.325-332, 2004.

PEUTZFELDT, A.; SAHAFI, A.; ASMUSSEN, E. Characterization of resin composites polymerized with plasma arc curing units. Dent Mater, v.16, p.330-336, 2000. 
PRICE, R.B.; EHRNFORD, L.; ANDREOU, P.; FELIX, C.A. Comparison of quartztungsten-halogen, light-emitting diode, and plasma arc curing lights. J Adhes Dent, v.5, p.193-207, 2003.

PRICE, R.B.; MURPHY, D.G.; DÉRAND, T. Light energy transmission through cured resin composite and human dentin. Quintessence Int, v.31, p.659-667, 2000.

RATIH, D.N.; PALAMARA, J.E.; MESSER, H.H. Temperature change, dentinal fluid flow and cuspal displacement during resin composite restoration. J Oral Rehabil, v.34, p.693-701, 2007.

RUEGgeberG, F.A. Contemporary issues in photocuring. Compendium, v.20, p.S4-S15, 1999.

RUYTER, I.E.; ØYSÆD, H. Conversion in different depths of ultraviolet and visible light activated composite materials. Acta Odontol Scand, v.40, p.179-192, 1982.

SAHAFI, A.; PEUTZFELDT, A.; ASMUSSEN, E. Soft-start polymerization and marginal gap formation in vitro. Am J Dent, v.14, p.145-147, 2001.

SAKAGUCHI, R.L.; BERGE, H.X. Reduced light energy density decreases post-gel contraction while maintaining degree of conversion in composites. J Dent, v.26, p.695-700, 1998.

SCHNEIDER, L.F.J.; CONSANI, S.; SINHORETI, M.A.C.; SOBRINHO, L.C.; MILAN, F.M. Temperature change and hardness with different resin composites and photo-activation methods. Oper Dent, v.30, p.516-521, 2005.

SHORTALL, A.C.; HARRINGTON, E. Temperature rise during polymerization of lightactivated resin composites. J Oral Rehabil, v.25, p.908-913, 1998.

SHORTALL, A.C.; PALIN, W.M.; BURTSCHER, P. Refractive index mismatch and monomer reactivity influence composite curing depth. J Dent Res, v.87, p.84-88, 2008.

SINGH, A.; MOHAN, B.; LAKSHMINARAYANAN, L. In vitro pulp chamber temperature rise during composite resin polymerization with different curing lights. Indian $\mathbf{J}$ Dent Res, v.16, p.92-98, 2005. 
STAHL, F.; ASHWORTH, S.I.I.; JANDT, K.D.; MILLS, R.W. Light-emitting diode (LED) polymerisation of dental composites: flexural properties and polymerization potential. Biomaterials, v.21, p. 1379-1385, 2000.

STANSBURY, J.W. Curing dental resins and composites by photopolymerization. J Esthet Dent, v.12, p.300-308, 2000.

STEWARDSON, D.A.; SHORTALL, A.C.; HARRINGTON, E.; LUMLEY, P.J. Thermal changes and cure depths associated with a high intensity light activation unit. J Dent, v.32, p.643-651, 2004.

TAHER, N.M.; AL-KHAIRALLAH, Y.; AL-AUJAN, S.H.; AD'DAHASH, M. The effect of different light-curing methods on temperature changes of dual polymerizing agents cemented to human dentin. J Contemp Dent Pract, v.9, p.57-64, 2008.

TARLE, Z.; KNEZEVIC, A.; DEMOLI, N.; MENIGA, A.; SUTALOA, J.; UNTERBRINK, G.; RISTIC, M.; PICHLER, G. Comparison of composite curing parameters: effects of light source and curing mode on conversion, temperature rise and polymerization shrinkage. Oper Dent, v.31, p.219-226, 2006.

TARLE, Z.; MENIGA, A.; KNEZEVIĆ, A.; SUTAlO, J.; RISTIĆ, M.; PICHLER, G. Composite conversion and temperature rise using a conventional, plasma arc, and an experimental blue LED curing unit. J Oral Rehabil, v.29, p.662-667, 2002.

TAKAHASHI, N.; KITAGAMI, T.; KOMORI, T. Evaluation of thermal change in pulp chamber. J Dent Res, v.56, p.1480, 1977.

TJAN, A.H.; DUNN, J.R. Temperature rise produced by various visible light generators through dentinal barriers. J Prosthet Dent, v.59, p.433-438, 1988.

TUNC, E.P. Finite element analysis of heat generation from different light-polymerization sources during cementation of all-ceramic crowns. J Prosthet Dent, v.97, p.366-374, 2007.

UHL, A.; MILLS, R.W.; JANDT, K.D. Polymerization and light-induced heat of dental composites cured with LED and halogen technology. Biomaterials, v.24, p.1809-1820, 2003.

UHL, A.; VÖLPEL, A.; SIGUSCH, B.W. Influence of heat from light curing units and dental composite polymerization on cells in vitro. J Dent, v.34, p.298-306, 2006. 
UNO, S.; ASMUSSEN, E. Marginal adaptation of a restorative resin polymerized at reduced rate. Scand J Dent Res, v.99, p.440-444, 1991.

WIGGINS, K.M.; HARTUNG, M.; ALTHOFF, O.; WASTIAN, C.; MITRA, S.B. Curing performance of a new-generation light-emitting diode dental curing unit. J Am Dent Assoc, v.135, p.1471-1479, 2004.

YAP, A.U.; LOW, J.S.; ONG, L.F. Effect of food-simulating liquids on surface characteristics of composite and polyacid-modified composite restoratives. Oper Dent, v.25, p.170-176, 2000.

YAP, A.U.J.; SENEVIRATNE, C. Influence of light energy density on effectiveness of composite cure. Oper Dent, v.26, p.460-466, 2001.

YAZICI, A.R.; MÜFTÜ, A.; KUGEL, G.; PERRY, R.D. Comparison of temperature changes in the pulp chamber induced by various light curing units, in vitro. Oper Dent, v.31, p.261$265,2006$.

YAZICI, A.R.; MÜFTÜ, A.; KUGEL, G. Temperature rise produced by different light-curing units through dentin. J Contemp Dent Pract, v.8, p.21-28, 2007.

ZACH, L.; COHEN, G. Pulp response to externally applied heat. Oral Surg Oral Med Oral Pathol, v.19, p.515-530, 1965. 
Anexo 
ANEXO A- Comprovante de envio do artigo referente à tese

Edit Accounk | Instructions \& Forms | Log Out | Get Help Now

Submission

Confirmation

Thank you for submitting your manuscript to Journal of Biomedical Materials Research: Part $A$.

Manuscript ID: JBMR-A-08-0917

Title: Composite photopolymerization: temperature rise according to light source and dentin thickness

Savaris, Cristiane

Chinelatti, Michelle

Authors: Lima, Fabricio

Bachmann, Luciano
Palma-Dibb, Regina

Date Submitted: $18-$ Nov-2008 Manuscript Central ${ }^{\mathrm{TM}} \mathrm{v} 4.11$ (patent $\$ 7,257,767$ and $\# 7,263,655$ ). O ScholarOne, Inc., 2008. All Rights Reserved.
Manuscript Central is a trademark of ScholarOne, Inc. ScholarOne is a registered trademark of ScholarOne, Inc. Terms and Conditions of Use - ScholarOne Privacy Policy - Get Help Now 